CUPAUAM 24, 1997, pp. 209-252

\title{
SOBRE TECNOLOGIA ROMANA: ALGUNOS DATOS EN TORNO A LA FABRICACIÓN DE ELEMENTOS ARQUITECTÓNICOS
}

\author{
OLIVA RODRÍGUEZ GUTIERREZ \\ Universidad Autónoma de Madrid
}

\section{Resumen}

Admiramos en ias grandes edificaciones clásicas sus monumentales elenentos arquitectónicos; entre ellos algunos de los más llamativos para profanos y especialistas son las basas, fustes y capiteles. Pocas veces nos cuestionamos cuáles fueron los procesos que hicieron que. desde un firente de cantera, la piedra llegara a formar parte de templos, basílicas, pórticos. A continuactón se presentan algunos datos sobre la fabricación. transporte y ensamblaje de elementos arçuitectónicos en época romana, recuriendo para ello a algunos ejemplos italicenses. No es fácil encontrar homogenetdad: según los lugares, la calidad y posibilidades de la piedra, o el periodo cronológico, se optará por unas u otras técnicas. La información la aportan, por un lado. las canteras y los elementos inacabados abandonados. por otro. las propias piezas ya finalizadas que. lejos hoy de su lugar original de ubicacion, muestran esas marcas y huellas que, en su momento, quedaban ocultas a los ofos del observador.

\begin{abstract}
We admire the monumental architectural elements in the great Classical buildings -among which bases. shafts and capitals stand out as some of the most atractive for both profars and specialists. However, we seldom ask ourselves about the processes that made these old stones travel from quarries to the temples, basilicae, porticus in which we find them now. In the following article we give some information about these fabrication, transport and attachment processes used in Roman times, including some examples from ltallca. It is not easy to find homogeneity: the choice of techrique varies depending on places, the quality and characteristics of the stone, and the chrononological moment. The information comes from quarries and unfinished elements, as well as from finished pieces that today -removed as they are from their original places-show marks that were in old times hidden to the observer's eyes.
\end{abstract}

Al contemplar los restos de los edificios romanos que han llegado hasta nosotros, pocas veces reparamos en la monumentalidad que por sí mismos ofrecen los ele- 
mentos arquitectónicos que componen su epidermis. Las basas, fustes y capiteles son solamente algunas de estas piezas, si bien se trata de las más fácilmente clasificables y también por ello las que hasta el momento han sido objeto de mayor número de estudios y de elaboración de corporal. No obstante, un análisis pormenorizado de este tipo de elementos nos lleva a cuestionarnos acerca de la tecnología empleada en época antigua para su fabricación así como los métodos y sistemas de producción que favorecian su elaboración y transporte hasta su lugar de destino. Del mismo modo, no habria que olvidar los mecanismos, técnicas y maquinaria que permitian que, una vez acumulados al pie del edificio correspondiente, ocuparan su emplazamiento definitivo.

A lo largo de todo el territorio ocupado por el Imperio romano se han recogido numerosos datos que reflejan un panorama muy diverso según los casos y que, si bien demuestran la preferencia por determinadas prácticas, no permiten afirmar que unas normas generales rigieran el trabajo ya fuera en canteras, edificios en construcción o talleres. A pesar de esta diversidad y, para ilustrar con algunos ejemplos el presente trabajo, incluimos algunas piezas procedentes del teatro de Itálica. Se trata de un edificio del que se ha conservado un importante número de elementos constructivos, muchos de los cuales, por no haber sido aún integrados en su restauración ${ }^{2}$, permiten ser analizados de forma detallada.

Entre las diversas marcas identificadas sobre las piezas se han distinguido tres grandes grupos según la fase de los trabajos a la que se asocien: fabricación, transporte ${ }^{3}$ y ensamblaje. No obstante, también su naturaleza sugiere una triple clasificación, pudiendo combinarse ambas:

- Líneas guia en los bloques, para auxiliar en la realización de las piezas, o en éstas ya sernielaboradas para dar las pautas a su futura decoración.

- Oquedades de diversa morfología: mortajas de grapas, espigas para pernos metálicos, canales de evacuación del metal sobrante, etc. Suelen estar asociadas al ensamblaje y unión de las piezas entre sí en su ubicación definitiva, sin embargo, en ocasiones, también pudieron ser útiles en la fase previa de transporte y elevación.

- Letras y/o signos incisos. Pueden responder a diversas fases de la elaboración de las piezas: de cantera, de almacenaje, indicador de posición en el edificio, etc.

${ }^{1}$ Entre ellos cabe destacar los de Kăhler, 1939; Scrinari, 1952 y I956; Belloni, 1958: Heilmeyer, 1970: Rossignani. 1975 o Pensabene, 1973, para ejemplares extrapeninsulares. A su vez, los de La Barrera, 1984: Diaz Martos. 1985: Gutrérrez Behemerid, 1992 o Márquez, 1993 son conocidos trabajos sobre capiteles hispánicos.

${ }^{2}$ Sobre esta intervención, fases y alcance véase Jimẹnez 1982 y 1989; Jiménez et alii, 1991 -92 y Rodríguez Gutiérrez, 1998, 115ss.

${ }^{3}$ Entendiendo por transporte los diferentes traslados sufridos por las piezas, o por la pledra en bruto antes de su elaboración, desde que salia de la cantera hasta que era ubicada en su lugar exacto de destino en el edificio correspondiente. 


\section{LA EXTRACCION: TRABAJOS PRELIMINARES DE CANTERA}

Las técricas a emplear dependian de la naturaleza geológica, las características físicas de los depósitos y la calidad de la piedra de los mismos (WARD PERKINS, 1992a, 16; KOZEL], 1988a, 4-5).

La búsqueda de determinadas vetas pudo llevar a la realización de túneles en la roca, si bien lo más frecuente fue la explotación de los afloramientos naturales al aire libre. Ocasionalmente se aprovecharon galerías abiertas por cursos freáticos de agua.

Se llevaba a cabo una explotación sistemática de las canteras, trabajando sus caras en sentido horizontal, vertical o ambos a la vez. Segun señala J. P. Adam ( $\left.{ }^{1} 1996.26\right)$, los canteros solian aprovechar las fisuras de la roca ya que esto suponía una economía no sólo de material sino también de tiempo de trabajo. Cuando lo anterior no era posible, la técnica empleada con mayor frecuencia para separar los bloques de la roca consistía en delimitar su perímetro por medio de incisiones realizadas a distancias regulares en las que se introducian cuñas de madera o metal (cuneî), ayudándose de martillos y mazas (malleoli y mallei). Las de madera, además, podían mojarse, lo que provocaba la dilatación del material y su aumento de volumen forzaba los orficios dando lugar a la rotura de la piedra (LUGLI, 1957, 219).

Según J. B. Ward Perkins (1992a, 16) existló otra técnica: se realizaba un puntilleado delimitando el bloque, y sobre él se ejercían presiones para desgajarlo del frente de cantera.

Era además importante que las canteras contaran con un medio de evacuación de la producción ya fuera por vía maritima, fluvial o terrestre.

A esta primera fase de extracción de bloques en la cantera se le denomina caesura. Dolci $(1989,17)$ señala diferentes categorías o técnicas para esta etapa de trabajo:

1. Percusión. Realizada con varios tipo de subulae (clavos y cuñas metálicas) y scalpra (cinceles), asi como de malleoli (martillos)"

2. Abrasión. Por medio de una serra (sierra) de hoja lisa o dentada simple o montada sobre un balancín de madera dotado de contrapesos.

3. Sección. Con cunei (cuñas) de hierro y/o madera que se aplicaban directamente a las litoclasas y a las fisuras del material y que se golpeaban con mallei (mazas). También se empleaban palancas.

4. Fragmentación y despiece. Por medio de mallet de grandes dimensiones.

5. Recuadrado y semielaboración. Con la ayuda de subulae, scalpra y malleoli de diversos tamaños. trabajo.

${ }^{4}$ Para una mayor precisión en la descripción del instrumental véase el último apartado del presente 
El grado de elaboración dado a las piezas en la cantera era diverso, dependiendo del tipo de pieza, la cantera y el material. No obstante, se tendió a un equilibrio entre la eliminación máxima de piedra superflua y la garantía de conservación de las piezas hasta su destino (ORTOLANI, 1989, 28). Una vez que bloques y/o piezas estaban preparados para su exportación podian inscribirse o pintarse sobre ellos diversas marcas, ya fueran de cantera o relacionadas con su punto de destino (BRuZZA, 1870; DuBOIS, 1908) ${ }^{5}$

Los bloques de piedra, cuando no recibían los rasgos de una tipologia determinada, debían ser al menos regularizados; por un lado, para favorecer el transporte, por otro, la comercialización. A partir de bloques paralelepipédicos era más fácil la subdivisión para hacer nuevas piezas. De nuevo se recurría a la inserción de cunei a lo largo de la que se pretendia, fuera la línea de rotura. Pudieron utilizarse otros elementos, a modo de cuñas metálicas complejas, cuyas partes iban siendo introducidas progresivamente en las ranuras realizadas, donde, a mayor volumen de hierro, se producía mayor presión, hasta que la piedra se rompia.

No obstante, también podía emplearse una sierra (serra, serrula), que producía un trabajo más perfecto y eficaz. Se necesitaban al menos dos serrarii. El tipo de piedra y el estado de la hoja de la sierra definían la calidad del resultado. En muchas ocasiones el plano de serrado queda interrumpido a pocos centimetros del límite de la pieza, conservándose la línea irregular de rotura del pequeño nexo de unión entre las dos partes (BESSAC, 1988, 44-46, fig. 7; MÁRQUEZ, 1996, 1131) (fig. 18).

\section{LA ELABORACIÓN DE LAS PIEZAS}

Las fases por las que pasaba un bloque de piedra desde que era extraído de la cantera hasta que era situado en un edificio, ya transformado en un elemento arquitectónico, eran numerosas. A su vez podian realizarse en diferentes momentos y lugares, sin que pueda establecerse un proceso uniforme para todas las épocas y áreas geográficas del Imperio.

Los pecios documentados con cargamentos pétreos, a pesar de ser escasos, son valiosos para analizar el grado de elaboración en el que eran transportadas las piezas (PEn. SABENE, 1978; KAPITÄN, 1971 y 1980; BEYKAN, 1988; PARKER, 1992).

Pensabene $(1972,332-333)$ señala cómo se constata la elaboración total de piezas para su exportación en época bizantina, mientras que anteriormente, a excepción de fustes y sarcófagos, aparecian tan sólo semielaboradas ${ }^{6}$.

Frente a otro tipo de elementos realizados en piedra como los sarcófagos, los elementos arquitectónicos estaban directamente vinculados al diseño unitario del edificio

\footnotetext{
${ }^{5}$ Vid. infra.

${ }^{6}$ A fines del siglo il d.C. circularian, procedentes de oriente, capiteles corintios totalmente terminados.
} 
para el se destinaban. P Pensabene (1972; 1986) ha sistematizado el proceso de fabricación en tres fases fundamentales:

1. Esbozado previo del bloque de mármol elegido definiendo a grandes rasgos su forma.

2. Ubicación del esquema ornamental de la pleza, una vez establecidos sus volúmenes.

3. Acabado de la pieza, generalmente en el lugar de destino, mediante la ejecución de sus detalles decorativos.

\section{Basas $^{7}$ (fig. 1)}

Siguiendo a N. Asgari $(1990,1992)$ su proceso de fabricación consistía en:

1. Se partia de un bloque paralelepipédico extraído de la cantera.

2. Se cortaba en cilindro parte de su superficie, con ayuda del pico de cantero $o$, en ocasiones, con un cincel apuntado. Podia realizarse de dos formas ${ }^{8}$.

2a) La altura inicial se dividía en tres partes, siendo el tercio superior el desbastado de forma cilíndrica hasta que su diámetro era aproximadamente dos veces la altura del bloque. Esta opción es la mejor documentada.

2b) La altura se dividía en dos partes, siendo en esta ocasión la mitad superior la trabajada en forma cilíndrica hasta que su diámetro era igual a la anchura del propio bloque.

3. De nuevo con el pico de cantero y el cincel, la parte inferior se regularizaba de forma cuadrada para configurar el plinto. El tercio intermedio era trabajado adoptando aspecto cilíndrico, siendo su diámetro igual al lado del plinto; se unía de forma oblicua al cilindro superior.

4. En este momento la basa estaba ya preparada para su exportación. No obstante, en ocasiones, en la propia cantera pudo llegarse a fases de elaboración más avanzadas. Así, por ejemplo, podian definirse mejor las aristas con un cincel plano y darse un mejor acabado a las superficies con un cincel gradillado.

\footnotetext{
${ }^{7}$ A partir del análists de basas inacabadas halladas en diversas canteras como las del Proconeso (AsGari, 1992) y las de Luni (Wakikens. De PAEPE y Móns. 1988, 110 ).

${ }^{8}$ En las canteras del Proconeso en época imperial las basas se realizaron en su mayor parte hasta la fase 2. Un mayor acabado fue más frecuente en época tardía.
} 


\section{FASES DE FABRICACIÓN DE BASAS DE COLUMNA}

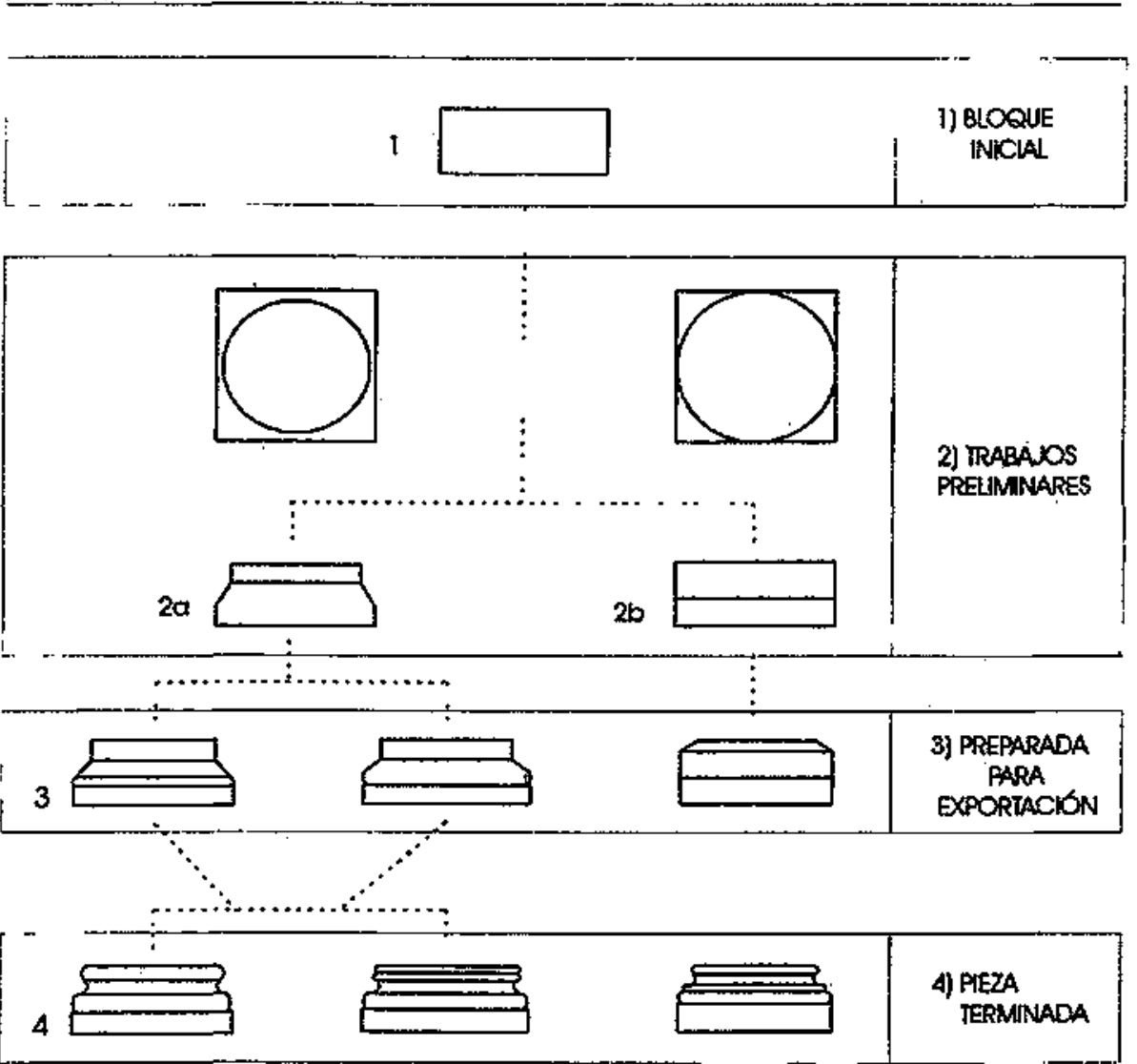

Figura 1.-Tabla expltcativa del proceso de fabricación de basas (modiftcada a partir de Asgari, 1992, 78, fig. 8)

A partir de esta fase las basas adoptaban las diversas formas que definian su tipologia que, no obstante, podía haber sido ya decidida según la división realizada en las fases anteriores ya descritas: ática, jónica, compuesta. así como otras variantes. En ocasiones, en la cantera, el tercio intermedio era transformado en un toro, o incluso se definian las diversas molduras que la configurarían. No obstante, lo más frecuente era que no se llegara a ese grado de finalización y que, manteniendo la vertical del cilindro de los dos tercios superiores, unas lineas incisas horizontales indicaran la separación de las diversas molduras ${ }^{9}$.

${ }^{9}$ En lo que respecta a este tipo de marcas y a la maquinaria empleada para realizarlas, véase como propuesta la presentada por G. Precht (1990) 
En las canteras del Proconeso se han encontrado basas cuyos plintos ofrecen sus esquinas y aristas sin desbastar por completo, con el fin de protegerlas (ASGARI, 1992. 77, fig. 6)

En el teatro romano de Itálica fue hallado, en el transcurso de las excavaciones de comienzos de los años setenta, un valioso elemento que informa sobre el diseño y fabricación de estas piezas. Se trata de una cornisa marmórea, exhumada en el hyposcaenium, desplazada de su lugar original de procedencia, la scaenae frons (fig. 2). En su parte superior se trazaron, valiéndose de punzón y compás, dos basas áticas de diferente tamaño pero, como defiende A. Jiménez $(1983,19)$, homotéticas, ya que las medidas de la mayor parecen ajustarse a múltiplos o submúltiplos del pie romano, mientras que la menor habría sido realizada por medio de proporciones a partir de la primera. Estos ejemplos podrían interpretarse como modelos en sí mismos para la fabricación de piezas o como pasos previos a la elaboración de plantilias, pero en ambos casos, demuestran, al menos, el acabado de las piezas en su lugar de destino.

\section{Fustes}

Tal y como indica N. Asgari (1992, 73), los procesos de fabricación no fueron los mismos para todas las piezas. En el caso de los fustes, éstos salian de las canteras con un mayor acabado que basas y capiteles (Pensabene, 1972, 322). La razón debe buscarse en que, con menor trabajo y menos cualificado, podian adquirir una forma cilindrica aproximada a la que debían presentar en su estado final, muchas veces incluso ya en el propio frente de cantera. Se han documentado ejemplos de ello en las canteras de Chemtou (Túnez) o Aliki (Isla de Thasos) (ADAM, $\left.{ }^{4} 1996,27\right)$, entre otras.

También se podian cortar bloques paralelepipédicos en sentido horizontal a los que posteriormente se les daba forma cilíndrica. Las vetas de la piedra, cuando las tenía. se solian dejar en la vertical ya que, al parecer, era más estético; sin embargo, la piedra cortada con las vetas en sentido horizontal soportaba mayor peso. Del mismo modo las columnas realizadas con tambores independientes (frente a los fustes monolíticos) resistian también mejor las presiones superiores.

Se definen las siguientes fases para la ejecución de los fustes:

1. Fase preliminar: se daba forma cilindrica al bloque longitudinal mediante un pico de cantero.

2. La superficie rugosa resultante era trabajada con un pico de menor tamaño y un cincel apuntado. Era en este momento cuando podian grabarse en sus extremos dos anillos a partir de los cuales se dejaba la pieza sin desbastar. Sus funciones eran varias: por un lado proteger estos extremos, que habrian de acoger el imoscapo y el sumoscapo, muchas veces moldurados; por otro, su 


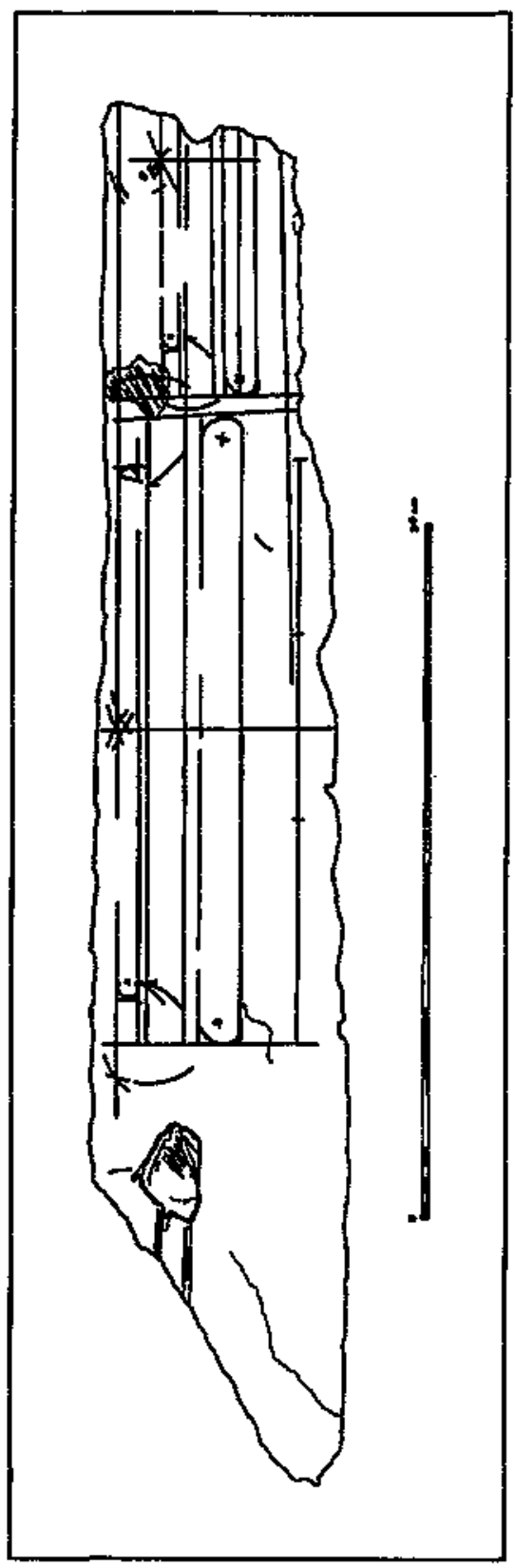

Figura 2.-Comisa hallada en el teatro romano de Itálica, perteneciente a su scaenae frons. En el bloque inicial, y antes de ser transformado en elemento arquitectónico se grabaron sobre él los diseños de dos basas áticas (jimenez, 1983. 18) 
profundidad podía definir los diámetros que en ambos sectores debía alcanzar la pieza una vez finalizada. No obstante, también seria frecuente que se exportaran de la cantera totalmente cilíndricas, sin esos anillos. Existen ejemplos de ello en las canteras del Proconeso y en los almacenes de la ciudad de Roma.

N. Asgari $(1992,73)$ ha reconocido también en el Proconeso algunas piezas que, siendo de longitud excesiva para ser tambores, podrian responder a encargos realizados a la cantera para la reparación de fustes monolíticos de edificios antiguos deteriorados.

5. En un tercer momento podian ejecutarse toda una serie de anillos horizontales a los largo del fuste a distancias determinadas. Tendrían aproximadamente 3 $\mathrm{mm}$. de profundidad y unos $2 \mathrm{~cm}$. de anchura (fig. 3).

4. A continuación se trabajaba la superficie rugosa del fuste entre los surcos horizontales anteriores con la ayuda de una gradina hasta alcanzar la profundidad de aquéllos, que así desaparecian. Tal y como señala Pensabene, a partir de su estudio de algunos ejemplares inacabados del pórtico del Coliseo (PENSABENE, 1992, 82), la profundidad de estos anillos habría marcado el perfil de contractura que debian ofrecer los fustes. Es posible que estas marcas vinieran ya realizadas de la cantera, tal y como ha documentado Asgari para el Proconeso, que auxiliarian y servirian de ayuda y de indicaciones para facilitar y dirigir su acabado. No obstante, el que no todos los fustes hallados en estas fases de preparación ofrezcan este anillado, ha hecho a P. Pensabene proponer dos hipotesis que incluso pueden ser simultáneas: que esta técnica fuera propia de piedras y/o canteras específicas; o que respondieran a encargos determinados según los cuales las piezas debían tener medidas muy concretas para ajustarse a las del resto de las columnas ya existentes, asegurando esos anillos la adecuación a lo solicitado (PENSABENE, 1992, 83).

El proceso anterior será valido para la realización de fustes lisos; no obstante a partir de éstos se podian obtener fustes estriados y torsos.

Sobre un fuste liso se realizarian una serie de marcas producto de cálculos geométricos que permitirian la ejecución de estrias verticales en toda su longitud. Se cree que, en líneas generales, se siguió el mismo proceso tanto en la parte superior como en la inferior de los fustes, si bien el peor estado de conservación del segundo de estos sectores ha impedido reconocerlo con total seguridad.

A partir de un estudio de A. Claridge (1983) sobre las columnas del Templo de Adriano en Roma, también llevado a cabo por C. Márquez para el caso de ejemplares de Corduba (MÁrQUEZ, 1996, 1123-1127) se han podido establecer las siguientes fases (fig. 4).

1. Sobre un fuste liso que ya cuenta con sus dimensiones y perfil de contractura definitivos, se traza una línea horizontal en el exterior próxima a las moldura de su sumoscapo, allí donde se sitúa el diámetro menor de la pieza. 


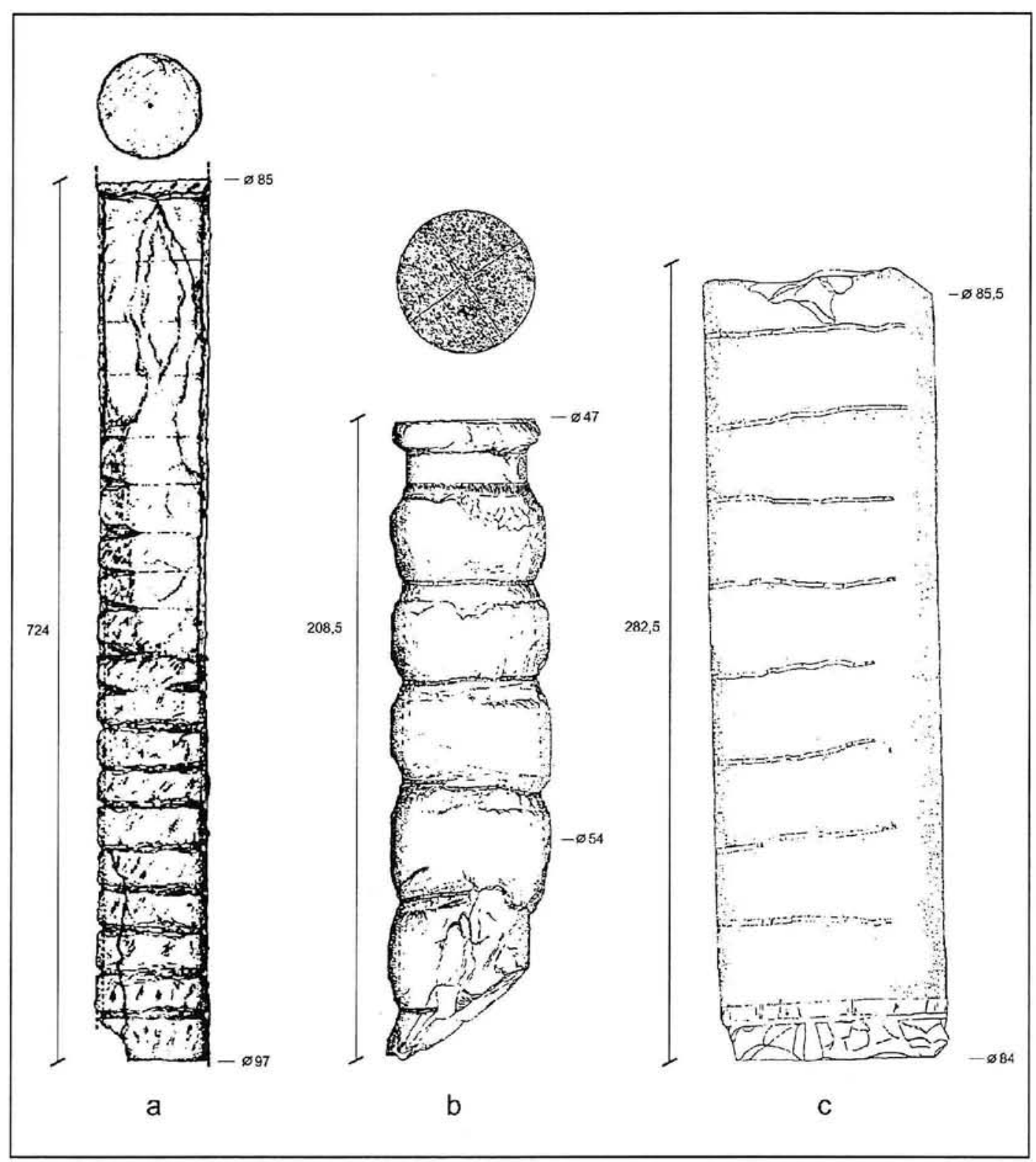

Figura 3.-Ejemplos de fustes inacabados del templo tetrástilo de Thignica (a), el Foro de las Corporaciones de Ostia (b) y el pórtico del Coliseo (c); en su superficie se trazó toda una serie de anillos para favorecer su realización. (Respectivamente de Pensabene, 1996, fig. 12 ; 1995, fig. 323 y 1992, fig. 10. Escalas diversas) 


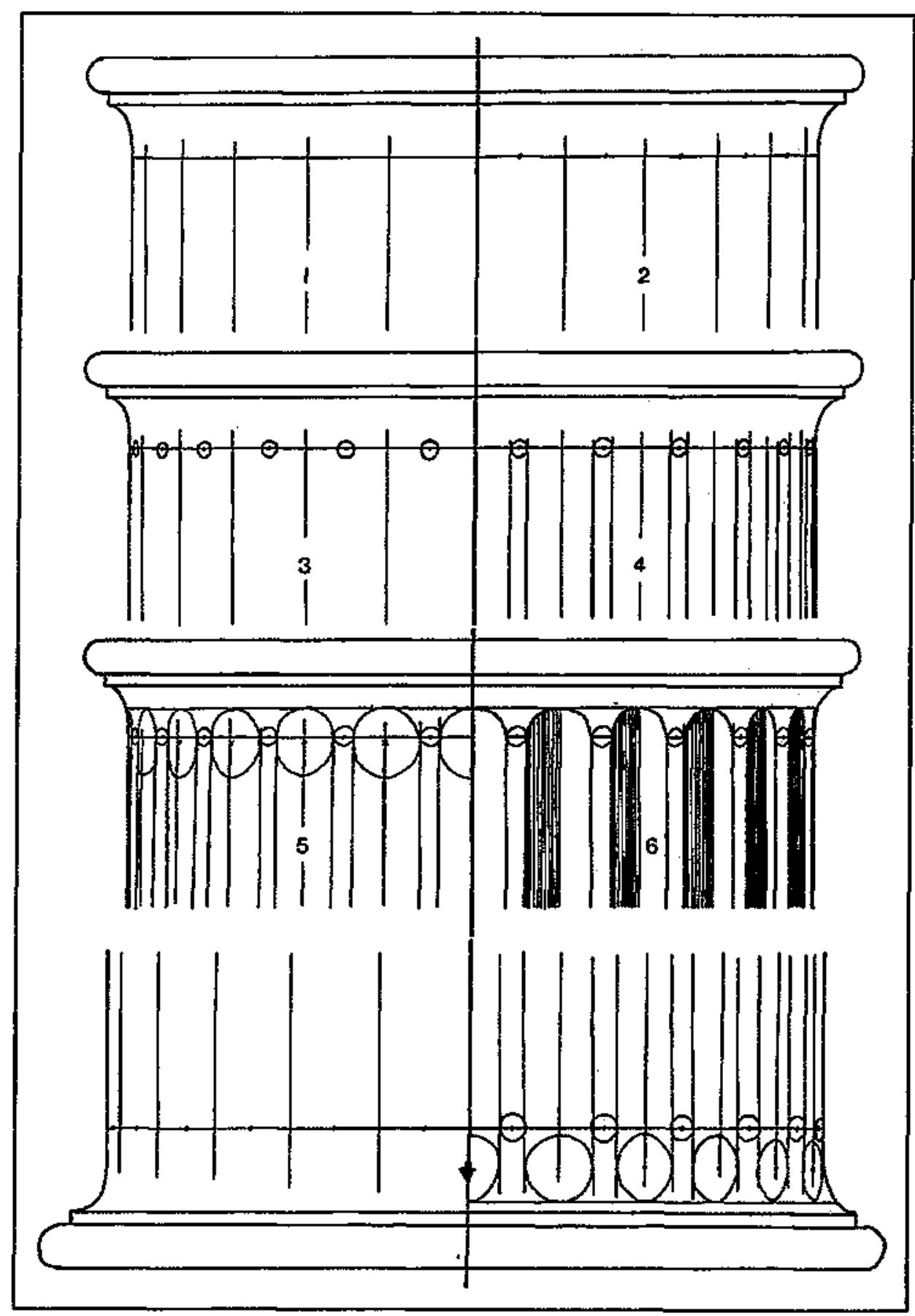

Figura 4.-Proceso de elaboración de un fuste estriado. (Según CLARIDGE, 1983, 124, fig. 12, a partir de columnas del Hadrianeum de Roma.) 
2. Se trazan líneas verticales paralelas, perpendiculares a la anterior, a la que cortan. No obstante, las acanaladuras segün se aproximan a la base del fuste se hacen más anchas y profundas. Para hallar estas lineas, la sección circular del fuste se dividia en ocho sectores iguales que volvian a dividirse cada uno de ellos en tres partes, dando como resultado veinticuatro puntos, tantos como acanaladuras.

3. Se hallan las mediatrices de los segmentos resultantes anteriores. Éstas servirán como centro de pequeñas circunferencias de diámetro igual al grosor de las estrías. En ocasiones pueden documentarse dos circunferencias concéntricas con escasa diferencia entre sus diámetros que podrian indicar los límites máximo y minimo en el vaciado de las acanaladuras.

4. Tomando como centro los puntos donde las líneas verticales cortan a la horizontal ejecutada en primer lugar, se trazan nuevas circunferencias de mayor tamaño cuyo diámetro señalará la anchura de las acanaladuras. En su parte superior estas circunferencias serán aproximadamente tangentes a la línea inferior de la moldura del sumoscapo (a la superior de la del imoscapo en el caso del sector inferior del fuste). Las acanaladuras, arriba y abajo, se rematan por cuartos de esfera. Ya se ha definido por tanto el contomo de las acanaladuras rectas, semicirculares en sus extremos.

5. Para desbastar éstas se emplearian, para darle su forma inicial, un cincel apuntado: se vaciaban con la ayuda de una gradina y, por último, con un cincel plano se les daba la forma definitiva. Su superficie final era obtenida, primero, trabajando en todas direcciones para eliminar las irregularidades de la piedra para, posteriormente, dar fuertes pasadas en horizontal, buscando imitar las bandas naturales del mármol.

6. Las estrías por el contrario, los filetes situados entre las acanaladuras, presentaban una superficie pulida, ya que se trataba de la original del fuste.

Si lo anterior corresponde al proceso seguido para la fabricación de fustes estriados monolíticos, en el caso de los realizados por medio de tambores, es de suponer su factura en su lugar de ubicación definitiva, a fin de hacer coincidir a la perfección entre todas las piezas las acanaladuras de su perimetro.

Para la obtención de un fuste torso (fig. 5), se realizaba una retícula sobre su superficie exterior formada por líneas verticales paralelas y perpendiculares horizontales. A continuación, las líneas oblicuas resultantes de las intersecciones de las anteriores senalaban el lugar de ubicación de las estrias helicoidales, que se desbastaban aproximadamente siguiendo técnicas semejantes a las ya descritas para los fustes estriados.

No obstante, hay que tener en cuenta que cada taller y/o cantera tendria sus propios métodos. Se emplearian diversos patrones para determinar el perfil de los fustes, incluyendo sus medidas, contractura, etc. En las canteras del Imperio se había llegado a tal grado de estandarización en la producción que permitía un cálculo autornático de las dimensiones del diárnetro menor del fuste y de sus proyecciones en imoscapo y sumoscapo (WILSON JONES, 1989, 48). 


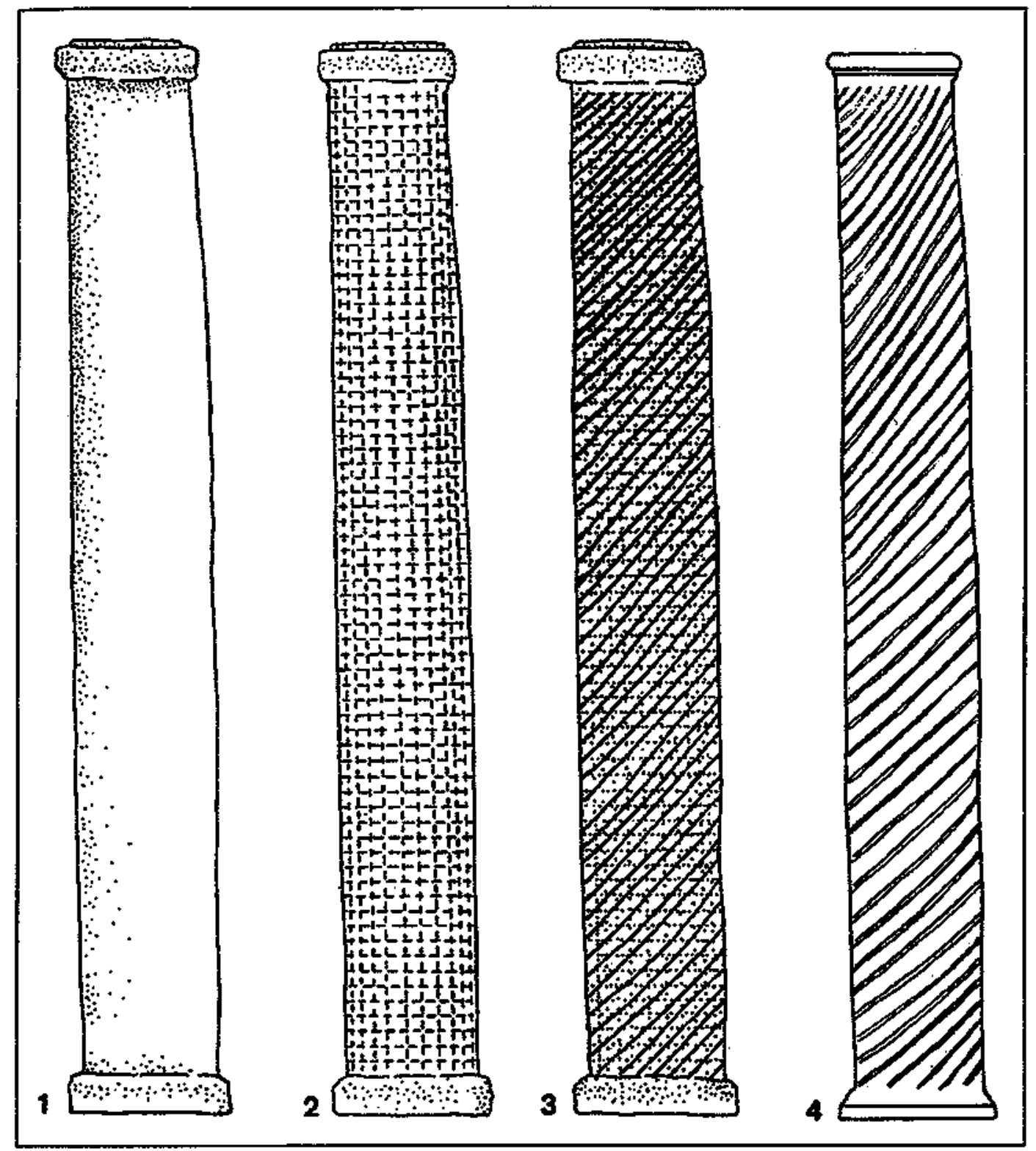

Figura 5.-Reconstrucción del proceso de elaboractón de un fuste torso

En un buen número de fustes hallados en el transcurso de las excavaciones realizadas en el teatro romano de Itálica, se ha documentado toda una serie de líneas geométricas trazadas con el fin de auxiliar en su elaboración, ya sea en su plano horizontal inferior (imoscapo), superior (sumoscapo) o en ambos. 
Entre ellas destacan, por un lado, la circunferencia que definía el diámetro del fuste y que por tanto en el imoscapo quedaría al interior del contorno exterior del mismo. Se aprecia en muchos casos también un punto central de compás, necesario para trazar la circunferencia citada ${ }^{10}$.

Otras líneas presentes con frecuencia son dos diámetros perpendiculares que dividen la circunferencia en cuatro sectores iguales. Parecen estar relacionadas ya no con la forma del fuste en sí mismo sino con la ubicación de sus orificios de ensamblaje (fig. 6, a,c-e).
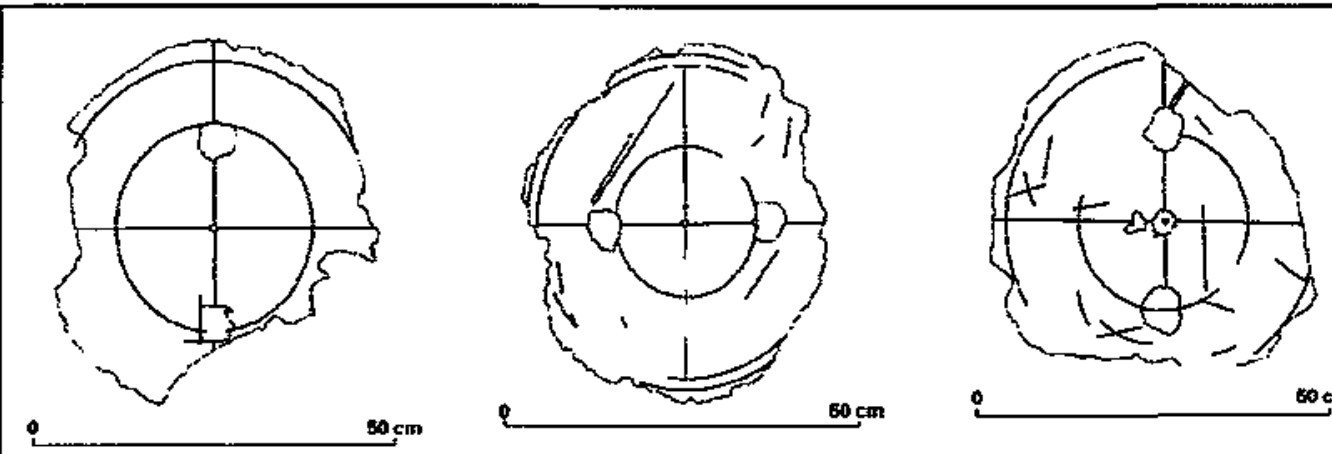

0

$60 \mathrm{~cm}$
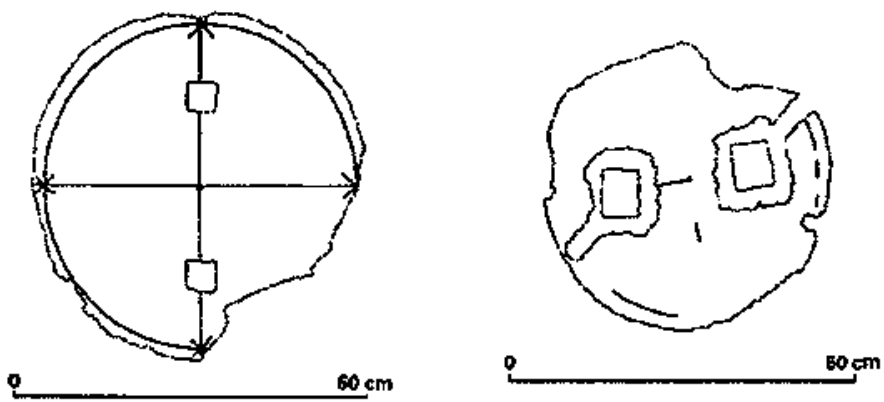

Figura 6.-Ejemplos de fustes del teatro romano de Itálica en los que se ha documentado el trazo de lineas para auxiliar en su fabricación y en la ubtcactón de sus oriftcios de ensarnblaje.

(Conde, 1994, figs. 1-5)

A pesar de que hay piezas que poseen además toda una serie de trazos secundarios (fig. 6. b-c), las citadas circunferencias exterior e interior y los dos diámetros perpendiculares, son las líneas incisas realizadas con mayor precisión y profundidad. Sus características sugieren su realización por medio de un instrumento metálico de gran dureza: un compás en el caso de las circunferencias, una gubia o punzón para las líneas rectas.

${ }^{10}$ Este diámetro es la medida fundamental para el modulado de la columna. Véase Wilson Jones (1989. 38-39) 
Si bien se observa uniformidad en la ubicación de las líneas y la manera de realizarlas. se aprecian variantes que indican la presencia de diversos operarios que, siguiendo diferentes criterios, obtuvieron idénticos resultados. De esta forma, con respecto a los pares de oquedades para cuya ubicación sirvieron, la circunferencia interior puede pasar por su centro, ser tangente exterior, o tangente interior a los mismos 0 , incluso, estar ausente (fig. $6 \mathrm{~d}$-e)

Al parecer, todo ello se llevó a cabo en Itálica o en un taller dependiente y no en la cantera, ya que se realizaron cálculos y procesos idénticos en fustes de mármoles de diversas procedencias. Por tanto no habría sido hasta que los mármoles fueron agrupados para su uso en el teatro cuando se comenzó a trabajar en ellos ${ }^{11}$ y a aplicar las reglas observadas, dependiendo de las necesidades arquitectónicas del edificio y sus órdenes.

Como señala Dodge siguiendo a Ward Perkins (Dodge, 1988, 72; Ward Perkins, 1992b, 25-26), la sistematización morfológica en la fabricación de fustes, dándoles unas medidas que les permitieran la fácil comercialización, hizo también más eficaz y rentable el trabajo de cantera ${ }^{12}$.

\section{Capiteles}

Para poder llegar a la uniformidad de las piezas dentro de un mismo programa decorativo, se seguian reglas geométricas estrictas que regían las relaciones de proporción entre las diferentes partes constituyentes de los capiteles. No obstante, su carácter artesanal y la diversidad de operarios hace que existan multiples variaciones entre las piezas.

A continuación se incluyen dos ejemplos documentados de los diversos procesos. que probablemente existieron en época clásica para la fabricación de capiteles corintios. A partir de ambos se habria obtenido un resultado muy semejante, lo que, de nuevo, demuestra la ausencia de unas normas estrictas para la obtención de este tipo de elementos.

P. Pensabene (1973, 192-194) propone el siguiente, a partir del análisis de ejemplares ostienses ${ }^{13}$ :

1. Se partia de un bloque aproximadamente troncopiramidal que habia sido desbastado por medio de un pico de cantero. Sus superficies inferior y superior adoptaban forma cuadrada.

\footnotetext{
"No obstante, podrian proceder de un centro aglutinador de materales al estilo de los documentados en la ciudad de Roma.

${ }^{12} \mathrm{Al}$ igual que los fustes, los bloques para lastras de enlosados y paredes también fueron fabricadas muy a menudo siguiendo unas medidas convencionales.

${ }^{13}$ También reconocido en ejemplares procedentes del teatro italicense, como veremos más adelante (CONDE, 1994, 127; RODRIGUEZ GuTTÉRREZ, 1998, 315-316).
} 
2. Se marcaban las diagonales y los diámetros de ambos planos.

3. En la superficie inferior se trazaba una circunferencia de diámetro igual al del sumoscapo de su fuste correspondiente.

4. En la parte superior se inscribía dentro del cuadrado una circunferencia y, dentro de ella, un nuevo cuadrado de lados iguales al diámetro de base de la columna. Este cuadrado delimitaba la superficie portante del capitel que podía dejarse ligeramente en relieve constituyendo el scamillus (ORTOLANI, 1989, 27) (Fig. 7).

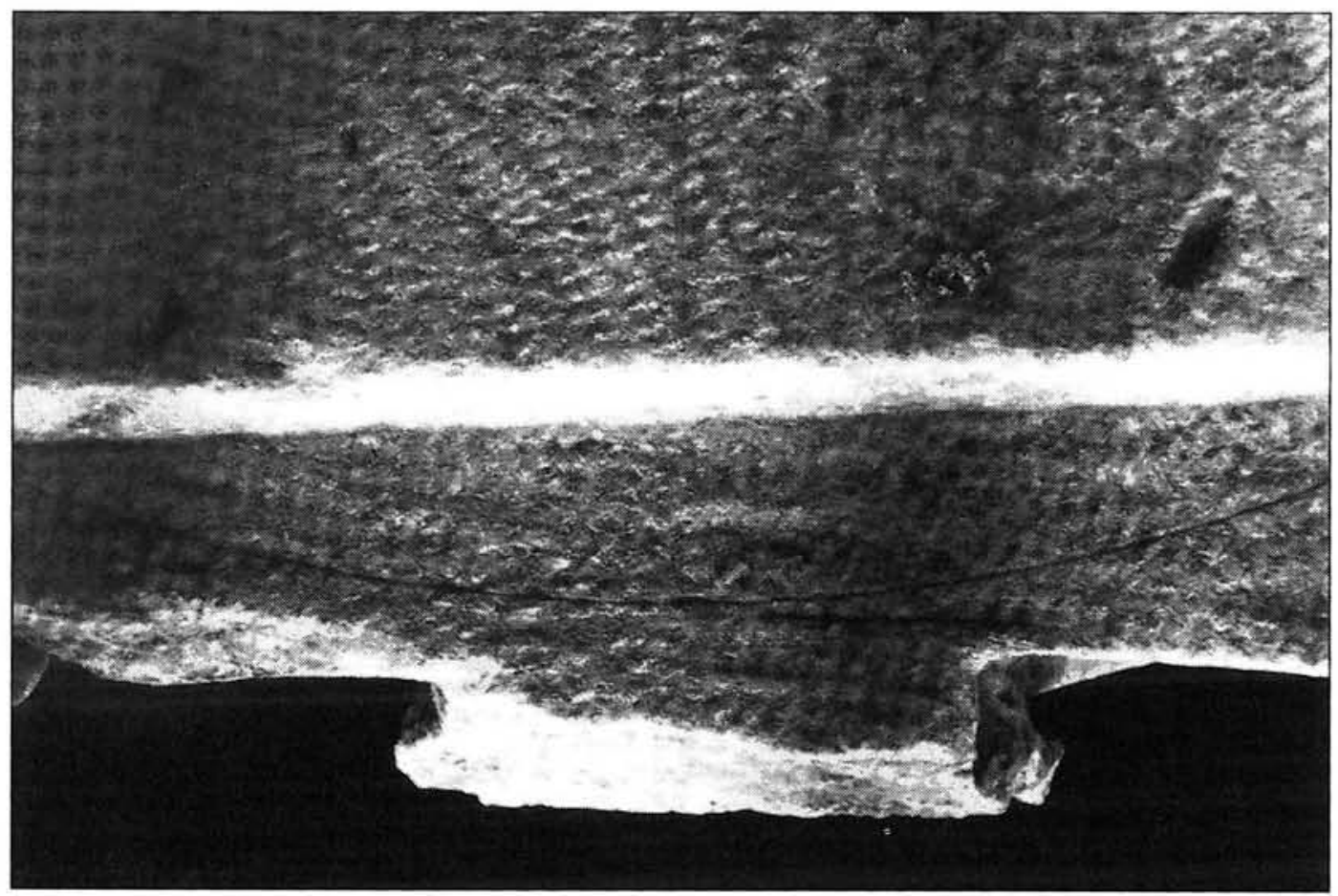

Figura 7.-Detalle de un capitel de la scaenae firons del teatro romano de Itálica en el que se aprecia la circunferencia trazada en la superficie del ábaco para auxiliar en el cálculo de sus dimensiones

5. La línea que atravesara los centros de las circunferencias que se inscribirían en esos cuadrados constituiría el eje central de la pieza. Sobre el cuadrado del ábaco los extremos de las diagonales indican la posición de sus ángulos (fig. 8); los diámetros la de las flores del ábaco.

6. El arco de círculo que definía la curvatura de los lados cóncavos del álaco tenía su centro en el vértice superior de un triángulo equilátero con base igual al lado cuadrado del ábaco. 
7. Los extremos de las diagonales del cuadrado y los diámetros de la circunferencia de la base respectivamente, que proyectados en altura coincidian con los del plano superior, señalaban el punto de separación entre las hojas de la ima folia y el punto central de la base de las de la summa folla.

8. Por medio de incisiones o trazos pintados se señalaban en las paredes laterales las diversas zonas en las que se organizaba la decoración del capitel.

9. Se definía la decoración vegetal, pero ésta se conservaba lisa, sin las nervaduras o los lóbulos de las hojas.

10. Por último, el acabado definitivo, especialmente en los siglos I y II d.C., se llevaba a cabo en el lugar de empleo ${ }^{14}$ Era entonces cuando se realizaba la decoración vegetal, con un auge del uso del trépano en época trajano-adrianea. No obstante, también podian dejarse sin trabajar aquellos sectores de las piezas que quedaran ocultos dado su lugar de ubicación en el edificio ${ }^{15}$

El único capitel completo conservado del orden de la scaenae frons del teatro romano de Itálica presenta los rasgos propios de algunas de las fases descritas. En su base ofreció dieciséis puntos, de los que hoy sólo se conservan catorce debido al deterioro de la pieza. Todos ellos son equidistantes a un punto central también marcado, y a su vez paralelos al límite circular exterior En el plano superior del ábaco dos rectas perpendiculares se cortan generando cuatro cuadrantes no idénticos; sus extremos coinciden con la ubicación de las flores de ábaco. Al exterior del scamillus se aprecia una circunferencia de diámetro igual al de la base de la pieza. Finas líneas incisas señalan también las diagonales del ábaco (figs. 7-9). Lineas semejantes han sido también identificadas en algunos otros fragmentos de capitel adscritos a esta serie de los dos órdenes columnados de la scaenae frons del edificio italicense.

En el caso del Proconeso, a partir de materiales abandonados en la isla en diversas fases de elaboración, N. Asgari $(1988,115-118)$ ha reconocido las siguientes fases de elaboración (fig. 10):

1. Se comenzaba a trabajar sobre un bloque extraído del frente de cantera con la ayuda de un pico. Su altura se dividía en cinco partes iguales horizontales. El centro de su plano superior se mantenía fijo y a partir de él se trazaba una circunferencia, de diámetro aproximadamente igual a la mitad de la diagonal de dicha superficie superior.

${ }^{14}$ Esto parece documentarse en un relieve hallado en Capua en el que un sculptor talla la decoración de un capitel mientras una maquina elevadora (majus tympanum) iransporta un capitel hasta su lugar de destino. (Fig. 11).

${ }^{15}$ Esta razón es la que se ha querido ver para el origen del capitel corintio de hojas lisas. En Roma se ha identificado por primera vez en los órdenes superiores del Tabularium (GUTERRRZ, 1992, 153) 


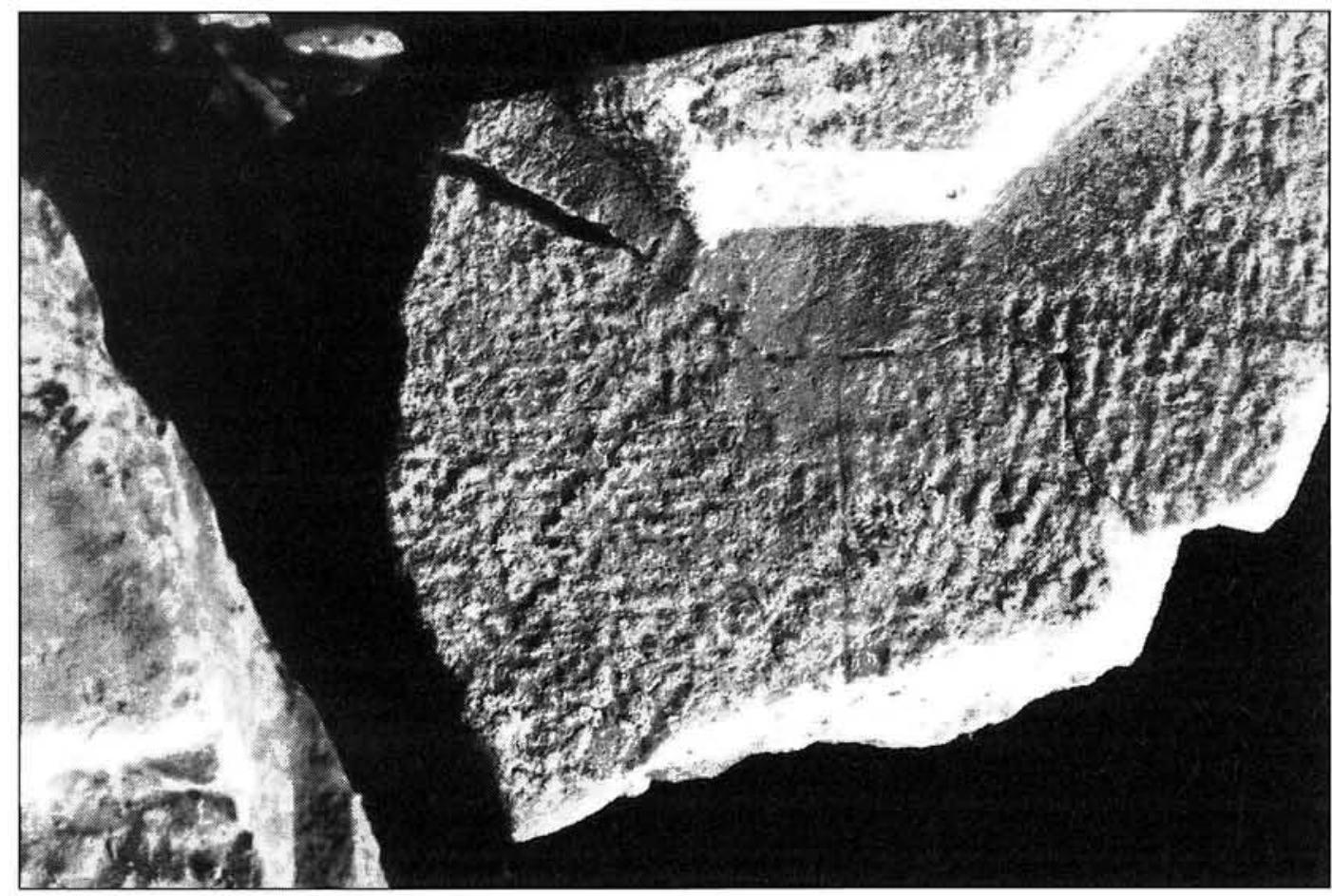

Figura 8.-Nuevo detalle del capitel anterior en el que se aprecian las líneas rectas que en la superficie del ábaco indican la disposición de sus esquinas

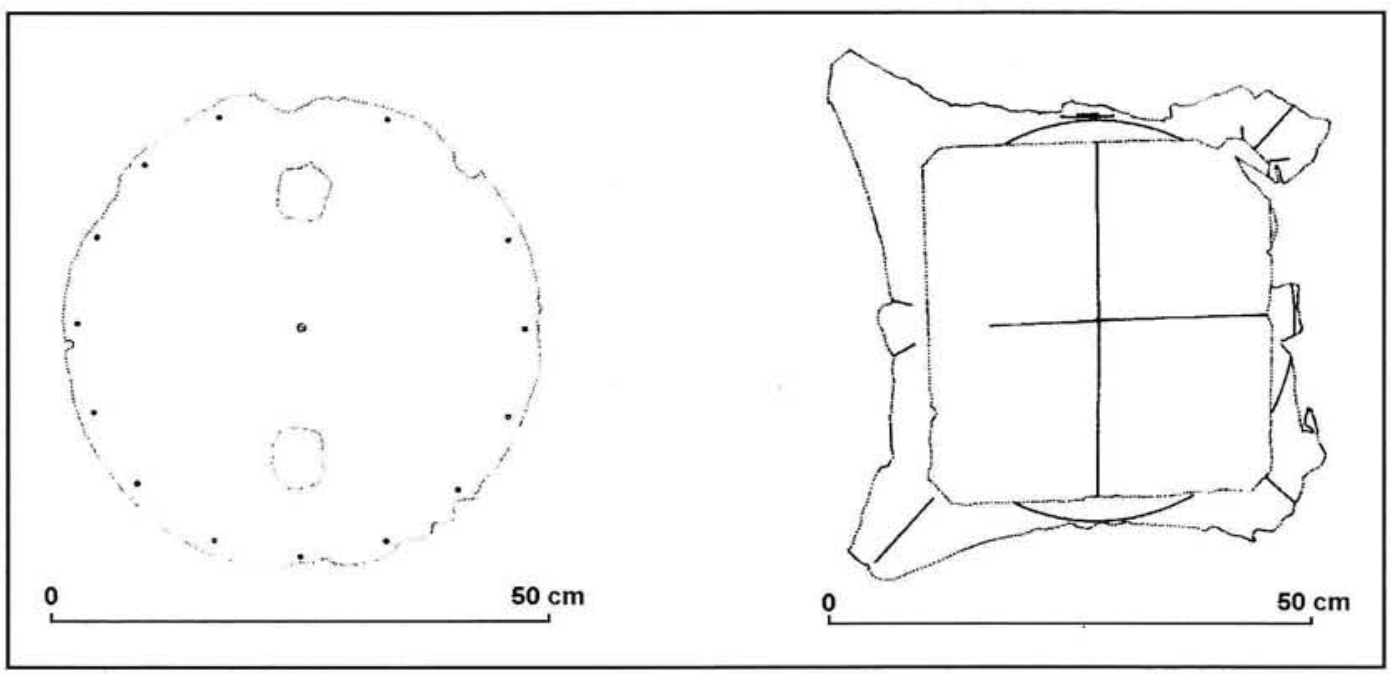

Figura 9.-1)ibujo del plano de la base y del ábaco del capitel completo del orden superior de la scaenae frons del teatro romano de Itálicà. (Según Conde, 1994, figs. 8 y 9) 


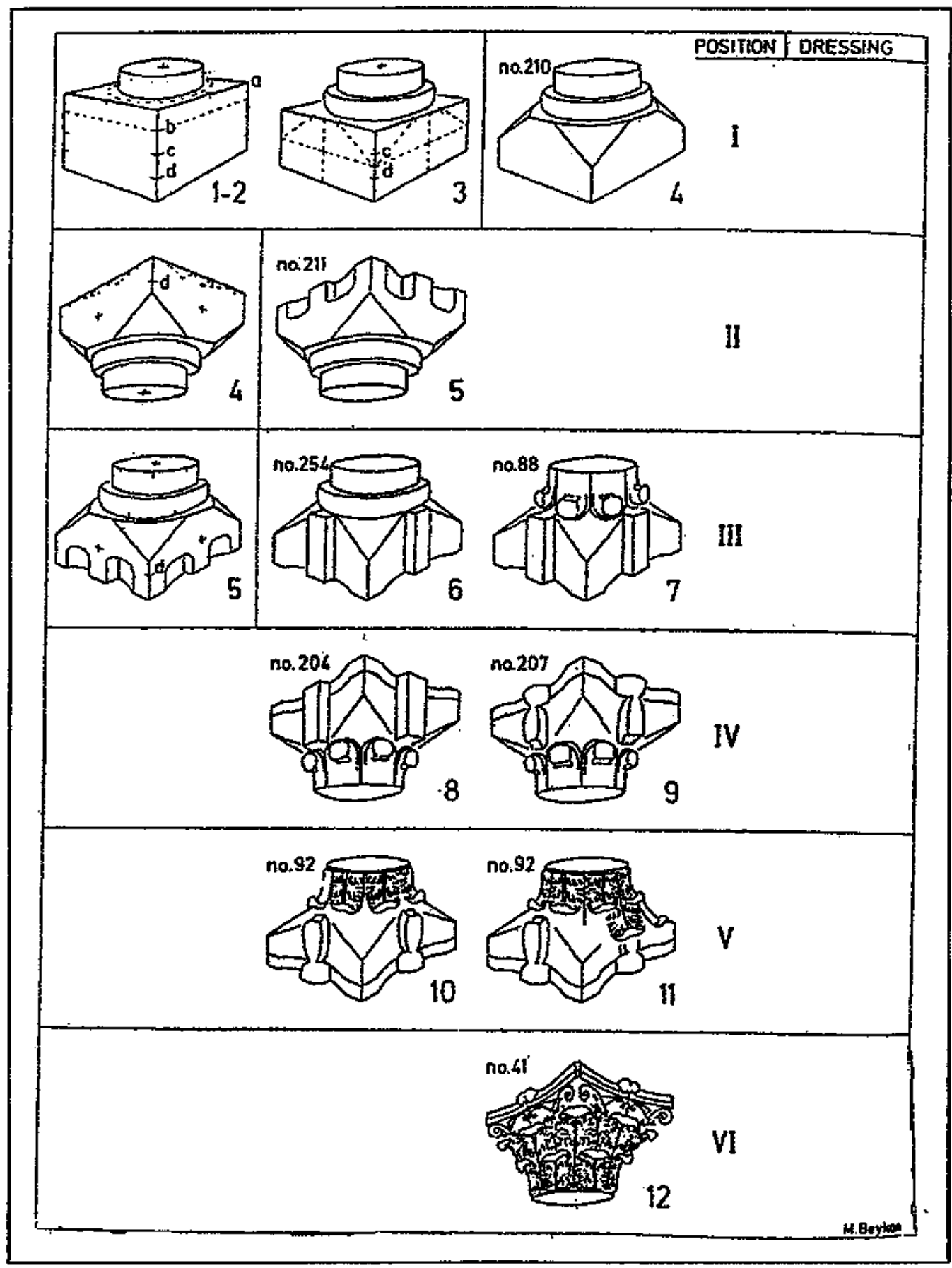

Figura 10.-Proceso de fabricación de capiteles de orden corintio. reconstruido a partir de los ejemplares inacabados hallados en las canteras del Proconeso (Asgari, 1988, 122, fig. 1) 
2. Con ese diámetro se daba forma cilíndrica a $1 / 5$ de la altura total del bloque que pasaba asi a constituir la base del futuro capitel.

3. Bajo el anterior y con diámetro algo mayor que éste se trazaba otro cilindro a modo de un toro, de nuevo con una altura aproximada de $1 / 5$ de la altura total.

4. Hasta el momento la pieza era trabajada en una posición invertida con respecto a la que luego adoptara el capitel resultante. De esta forma se desbastaban con un pico las esquinas superiores, quedando una superficie oblicua en cada una de ellas sin llegar a alcanzar el toro, dejando hasta él una super ficie horizontal libre.

5. A continuación, y una vez girada la pieza, se trabajaba en lo que sería el ábaco. Se le da forma rectangular, dejando en cada uno de sus lados una protuberancia sobre la que más adelante se trabajarian las flores de ábaco. El plano superior se desbasta de manera tosca con un pico de cantero.

6. Las protuberancias dejadas en reserva en el ábaco se prolongan hasta llegar al plano horizontal sobre el toro. Quedan asi configurados cuatro rectángulos prismáticos verticales desde el ábaco hasta el toro.

7. El toro se divide en ocho partes que se trabajaban dando forma a otros tantos abultamientos separados entre sí por incisiones a distancias y anchuras regulares. Se tendría en cuenta que éstas coincidieran con los ejes de la pieza, ya que aquéllos, los abultamientos citados, alojarian a cada una de las hojas de la ima folia. Hasta este momento casi todos los pasos pudieron hacerse con el empleo exclusivo del pico de cantero.

8. El plano superior del ábaco podía recibir ahora un mejor acabado por medio de una gradina (BESSAC, 1988, 47), del mismo modo que una línea incisa horizontal indicaba el límite de su moldura ${ }^{16}$.

9. Los rectángulos verticales dejados en reserva se dividen en dos, siendo de menor tamaño el sector destinado a la flor del ábaco.

10. Se trabajaba la decoración de las hojas de acanto de la ima folia. Mientras que las fases anteriores se llevarian a cabo en la cantera a partir de este momento las realizarian operarios más cualificados en talieres próximos a puertos y otros puntos de distribución de las piezas.

11 y 12. Se llevaba a cabo el resto de la decoración vegetal del capitel: hojas de la summa folia, cauliculos, cálices, hélices, volutas, flores de ábaco, etc. (fig. 11).

Es muy posible, especialmente para los capiteles decorativos de lesena, que existieran cartones a modo de catálogos con los diversos modelos. Según P. Pensabene

\footnotetext{
${ }^{16}$ Que, no obstante, en adelante podria ser subdividida en otras dos: óvolo y caveto, a su vez susceptibles de presentar su superficie decorada.
} 
$(1973,189)$ es prueba de ello la existencia de motivos iguales sobre mármoles diferentes y sobre el mismo típo de mármol pero hallados muy alejados geográficamente. También se han encontrado calcos de yeso a tamaño natural para favorecer la copia e imitación de las piezas.

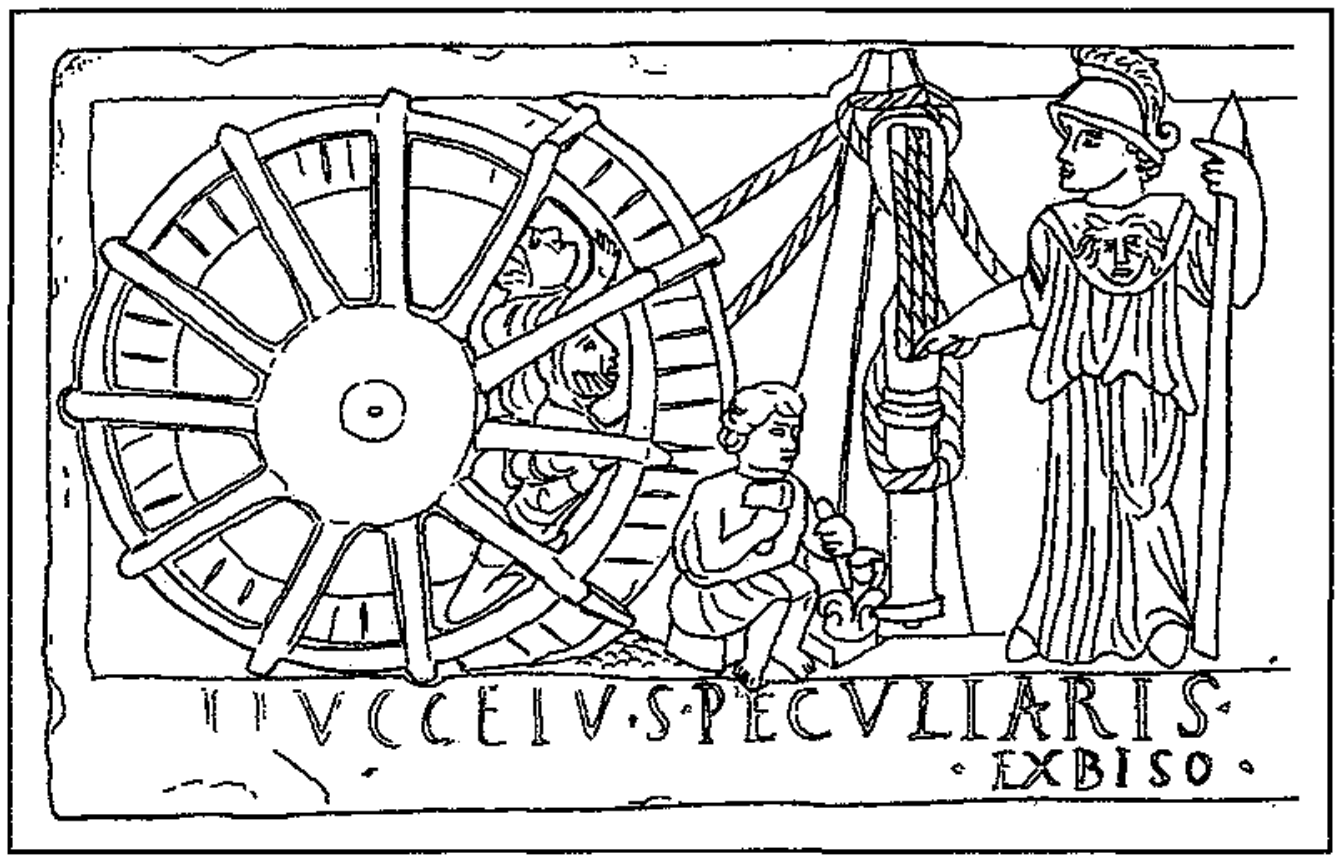

Figura 11.-Relieve de Capua en el que aparece un operario elaborando un capitel; tras él una máçuna elevadora levanta un fuste de columna (tomado de Adam, '1996, 48, fig.92)

\section{OQUEDADES Y MORTAJAS PARA GRAPAS Y PERNOS COMO AUXILIO EN LAS LABORES DE TRANSPORTE, ELEVACIÓN Y ENSAMBLAJE}

Muchas piezas ofrecen orificios para posibilitar y facilitar su transporte; son de cantera, de oficina o de obra. Éstos eran generados con el fin de hacer uso de los diversos sistemas de transporte y elevación difundidos en época romana (ADAM, ${ }^{4} 1996,49-53$ ), si bien algunos de ellos procedian de la tradición griega (LuGLI, 1957, 227ss.).

El transporte era lo que más encarecía los costes de los elementos arquitectónicos. Por ello, en la medida de lo posible, se buscaban puntos de extracción lo más cercanos posible a vías de distribución, prefiriéndose las maritimas y fluviales, dado el peso de los materiales a transportar ${ }^{17}$. 1988, 56-57)

17 Sobre los diversos sistemas de transporte segün la ubicación de las canteras (véase WuRCH-KozEij, 
Los bloques pueden presentar espigas sobresalientes en sus laterales, los llamados ancones, para, por medio de cuerdas y amarres, elevarlos. Se ubicaban de forma simétrica en las piezas para evitar que éstas se desequilibrasen y cayeran. Se evitaba su empleo en piezas muy pesadas, si bien la dificultad de documentar su uso viene también dada por su eliminación una vez en su lugar de ubicación definitiva.

Cuando lo que se documentan son oquedades en las piezas, según su naturaleza, responden al empleo de diversos sistemas. Si se encuentran en el centro de gravedad del bloque y su sección es de paredes inclinadas, se debia a la castañuela, formada por tres piezas metálicas, las laterales de perfil oblicuo y la central recta, que, al unirse, adoptaban forma de cola de milano. Las tres piezas metálicas se introducian progresivamente: las laterales de perfil divergente primero, la central recta en último lugar. Finalmente un clavo que atravesaba las tres piezas y una anilia permitían su elevación mediante cuerdas. También se han documentado arqueológicamente castañuelas de una y dos piezas. Para ajustar al máximo la unión sería frecuente el auxilio de pequeñas piezas metálicas y arena (LUGLI, 1957, 228) Este sistema tenía toda una serie de ventajas sobre el anterior: permitía elevar mayor peso, la preparación de los bloques era más rápida y fácil, y no habia que eliminar marcas una vez colocadas ya que, en la mayor parte de las ocasiones, quedaban ocultas. También han sido documentados orificios de paredes totalmente verticales. Adam sugiere que habrian sido realizados para emplear lo que él llama una castañuela auto-serrante, instrumento metálico de vástagos dentados que. introducido en la cavidad realizada en la pieza, al ejercer presión para alzarla, tendia a abrirse agarrándose a las paredes del orificio. Si lo que se empleaba eran los ferrei forfices (forceps, tenazas) las cavidades eran simétricas y se situaban en las paredes verticales de la pie$\mathrm{za}^{18}$. Con este instrumento metálico, a modo de pinzas, cuyos garnios se aseguraban en las citadas oquedades, se elevaban las piezas. A pesar de su eficacia, tan sólo permitian levantar las de igual o menor tamaño a la abertura máxima de las tenazas.

Para auxiliar en la elevación de las piezas se utilizaron principalmente la polea (trochlea, orbiculus) y el torno de mano (sucula) que, no obstante, fueron perfeccionados. hasta llegar a máquinas complejas que unian ambos sistemas (rechamum) ${ }^{19}$. Dentro de esa mayor complejidad se ha visto como por ejemplo la fuerza motriz encargada de mover el torno podía proceder de una gran rueda de madera (majus tympanum) dentro de la cual hombres caminaban para hacerla girar (fig. 11)

${ }^{18}$ R. Durán ha documentado y analizado las huellas presentes en gran número de los edificios púbilcos de Emerita Augusta, entre las que destacan las asociadas al uso de ferrei forfices o ferteus vectis como en los puentes sobre los rios Anas y Albarregas, el Templo de Diana o el teatro (DuRÁn, 1991-92, 48, 50, 58 y 61)

19 Vitruvio en el Libro X, cap. Iİ, 2, al hablar de las máquinas de tracción, y más concretamente de una de las máquinas empleadas en la construcción de los templos diră: "/... / ad rechamum autem imum ferrei forfices religantur, quorum dentes in saxa forata accommodantut Cum autem funis habet caput ad suculam religatum et vectes ducentes eam versant, funis se involvendo circum suculam extendiur et ita sublevat onera alitudinem et operum confocationes [.../ (El subrayado es nuestro.) 
Para asegurar la unión perfecta y duradera entre los diferentes elementos de una construcción en ocasiones se hizo uso de grapas (metálicas o de madera), pernos y espigas. Muchos de ellos hoy se han perdido pero han dejado sus orificios y lechos, cuyo análisis resulta de gran interés.

Las huellas de grapas podian ser de diversas formas: así la que primero se utilizó en el mundo romano fue en forma de doble cola de milano, tomada de la arquitectura griega pero procedente de las técnicas constructivas egipcias (OrTOLANI, 1989. 26) Se han documentado también rectas, en forma de doble $T$ y en pi $(\Pi)$

Serian fundamentales las uniones verticales, como en el caso de las columnas. Lo más frecuente era insertar primero una espiga metálica en la pieza superior en la que ya se había realizado previamente un orificio a tal efecto. A continuación se introducía en la cavidad correspondiente de la pieza inferior en la que se habia vertido metal fundido. Es frecuente encontrar canales que comunican los orificios con el exterior, cuya función era la de evacuar el metal líquido sobrante.

Otra variante era la anathyrosis que consistía en dejar parte de las superficies de unión entre las piezas desbastadas toscamente, pudiendo quedar rehundidas o en resalte: así se garantizaba una adhesión más perfecta entre ellas ${ }^{20}$ De esta forma, especialmente en el caso de los elementos arquitectónicos, se reducian también las presiones entre piezas inmediatas.

Entre las basas, fustes y capiteles hallados en el teatro romano de Itálica, un buen número de ellos presentan huellas que responden a alguna de las funciones anteriores, si bien no siempre será fácil distinguir a cuál de ellas, ya sea transporte, elevación o ensamblaje. De hecho es posible que un orificio hubiera asumido diversas funciones en momentos sucesivos de la vida de la pieza.

En las basas del conjunto estudiado tan sólo se documenta una oquedad cuadrada central. Alojaria la espiga metálica que a su vez había sido previamente introducida en el fuste de columna situado sobre ella (fig. 12).

En lo que respecta a los fustes los datos son más abundantes, por to que hemos creído conveniente sistematizar las diversas variantes (fig. 13):

a) Un orificio circular central y dos cuadrados laterales. Aparece tanto en planos de imoscapo como de sumoscapo.

b) Un orificio central, pudiendo adoptar diversas características:

- según su posición en el fuste: en el plano del imoscapo; en el plano del sumoscapo; en fragmentos centrales de fuste de extremos regularizados; en tambores.

${ }^{20}$ La anasthyrosis era empleada también para proteger los sectores más delicados de las piezas durante su elaboración siendo posteriomente eliminada; es lo que M. Wurch-Kozelj ha denominado con el ilustrativo nonbre de protective envelope $(1988,55)$. 


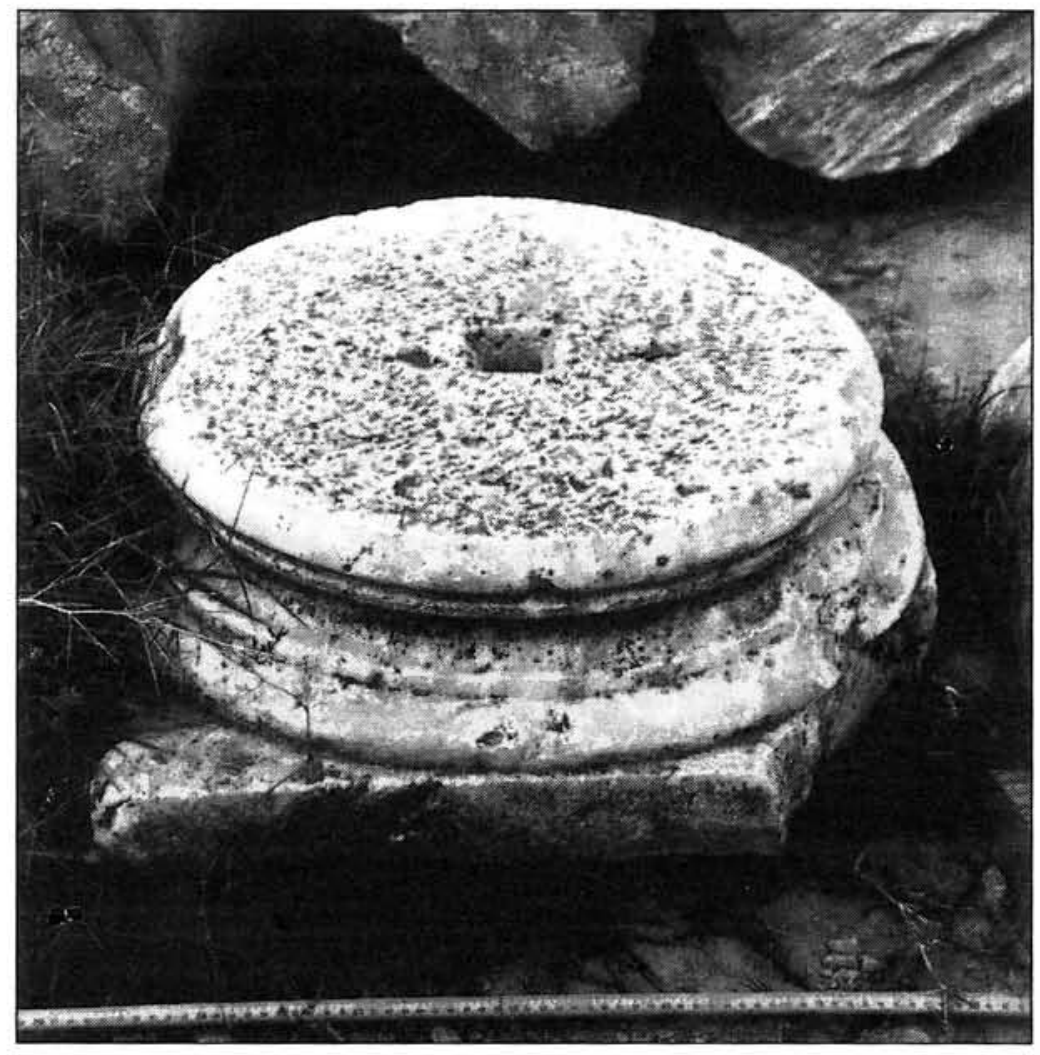

Figura 12.- Basa del orden inferior de la scaenae firons del teatro romano de Itálica con orificio central para asegurar la unión con su fuste correspondiente

- según su morfología: circulares; cuadrados; rectangulares; conectados con el exterior por medio de canales de evacuación del metal sobrante. Algunos conservan restos de éste.

- según su profundidad: desde superficiales (en torno a $1,5 \mathrm{~cm}$ ) a muy profundos (hasta un máximo documentado de $25 \mathrm{~cm}$ ); en el caso de los tambores estos orificios los atraviesan en toda su altura.

— según el tipo de fuste: en lisos; estriados; torsos.

- según el material de la pieza solore la que se han realizado: mármoles diversos; caliza fosilífera; arenisca.

c) Dos orificios simétricos:

- una pareja de orificios de sección cuadrada y escasa profundidad (oscila entre 3 y $8 \mathrm{~cm}$ ). 


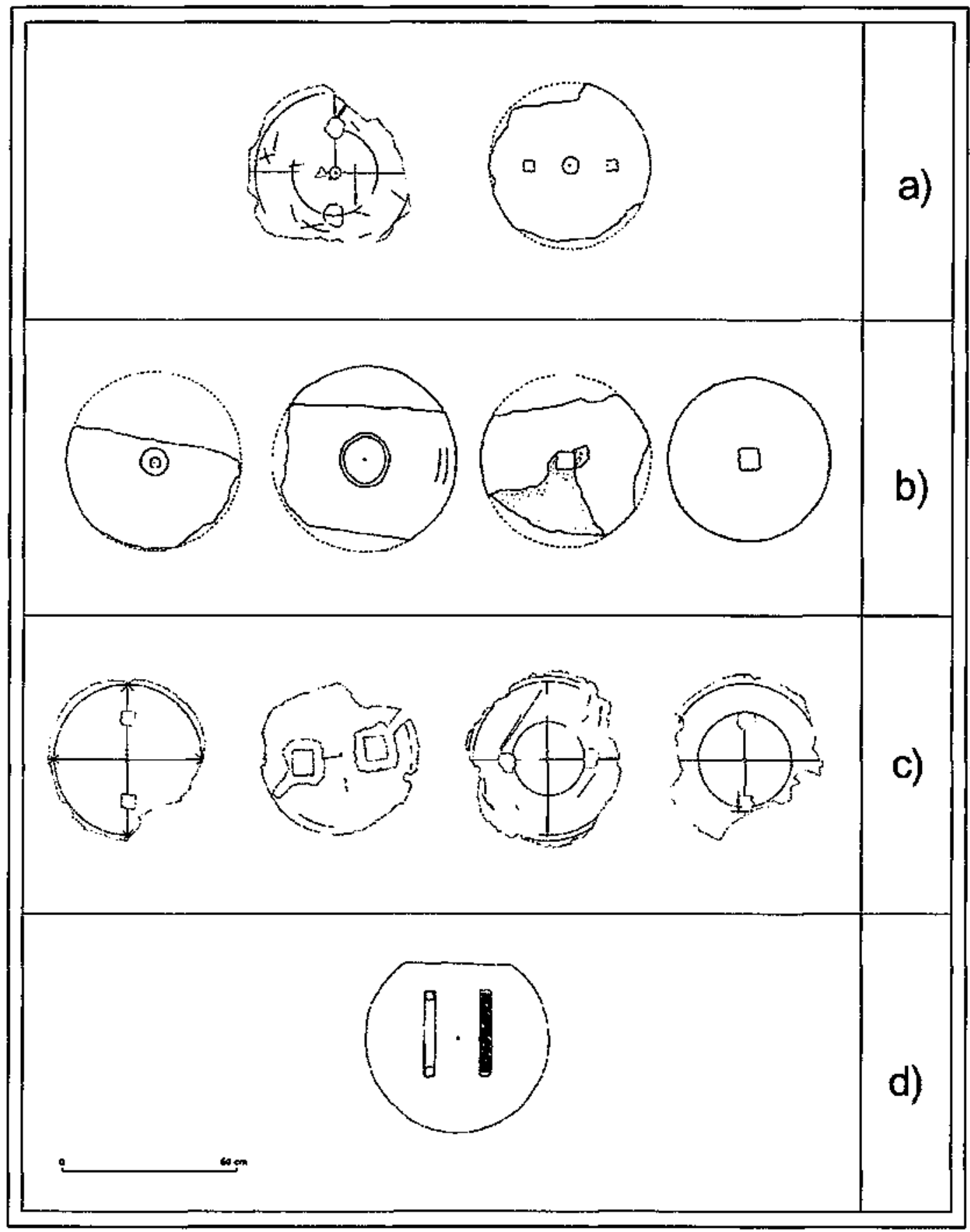

Figura 13.-Tabla en la que se han tratado de sistematizar las diversas variantes de cavidades documentadas en los fustes hallados en el teatro romano de Itálica 
- dos grandes rehundimientos de forma cuadrada y sección trapezoidal; presentan canales de evacuación de metal y tan sólo han sido documentados en la superficie de sumoscapos.

d) Dos cavidades simétricas rectangulares de escasa profundidad (2 $\mathrm{cm}$ aproximadamente) en la superficie dei sumoscapo. Conservan restos de grapas metálicas en $p i(\Pi)$.

En los capiteles lo más frecuente será encontrar oquedades en su base para facilitar y asegurar su unión al sumoscapo de su fuste correspondiente. Se han documentado orificios centrales, dos simétricos de forma cuadrangular (fig. 9) No obstante, se han hallado también ejemplares que, carentes de scamillus, presentan orificios en su ábaco para pernos metálicos encargados de la fijación del arquitrabe.

\section{ARTESANOS Y ESCUELAS}

Pero sin duda alguna un papel fundamental dentro del proceso de fabricación de piezas fue el desempeñado por los diversos operarios más o menos cualificados. Éstos las llevaban a cabo en cada una de sus fases, desde que la piedra era extraída del frente de cantera hasta que era situada en su lugar de destino correspondiente convertida en un elemento arquitectónico. Del mismo modo, estos trabajadores se organizaban en talleres que a su vez, según las características de la labor realizada, en muchas ocasiones muy estrechamente relacionadas con su lugar de origen (lo que les hacía expertos conocedores de la técnica a emplear con una piedra determinada), podian definir escuelas. Estas, en la mayor parte de los casos han sido definidas por la investigación actual pero. no obstante, nos consta su existencia en época antigua, como es el caso de la célebre Escuela de Afrodisias.

\section{Los artesanos}

P. Pensabene (1972, 352, nota 10) señala entre los artifices ${ }^{21}$ que participaban en el proceso de fabricación de elementos arquitectónicos y en el trabajo de la piedra en general:

En la cantera, el lapidicaesor era el encargado de extraer los bloques de la roca. El lapicida hacia las marcas guía sobre la piedra. El que llevaba a cabo la regularización de los bloques dándoles formas adecuadas para su transporte y comercialización respondía al nombre de quadratarius. El serrarius cortaba la piedra. A su vez el término marmorarius es muy amplio, pudiendo incluir prácticamente todas las fases del proceso. $\mathrm{El}$

${ }^{21}$ Sobre el término artifex, véase: Calabi Limentani, 1958, 9. 
nombre viene definido por el tipo de material que trabajaba, el marmor, teniendo en cuenta el significado de este término en época romana ${ }^{22}$.

De nuevo $P$ Pensabene $(1972,317)$ señala cómo estos operarios se agrupaban en collegia y es posible que, al igual que ocurría con los talleres especializados en la extracción de piedra en las canteras, se rigieran por una serie de principios formales y técnicos que obedecieran a una tradición generada por el uso, en aras también de una mayor funcionalidad.

En la officina, la presencia del lapidarius será muy frecuente. En el Edictum de Pretiis de Diocleciano se señala que su sueldo era diez denarios menor que el del marmorarius, también aquí presente ${ }^{23}$. Di Stefano Manzella $(1987,112)$ atribuye esta diferencia salarial a la calidad del trabajo realizado por ambos. El sculptor se encargaba del acabado escultórico de las piezas, como por ejemplo los motivos de capiteles y basas decoradas (Fig. 11).

P. Pensabene anota que la acusada especialización de los operarios no sería una prueba de elevado nivel técnico. Por el contrario, lo primitivo de los instrumentos y utensilios (fig. 16) obligaria a su creciente cualificacion para compensar las insuficiencias técnicas.

A pesar de los intentos llevados a cabo, especialmente por los estudios epigránicos, es poco y bastante confuso lo que puede obtenerse sobre las tareas, fases de elaboración y jerarquiáa de los empleados de los talleres (DI STEFANO, 1987, 54). No obstante, para el ámbito de las relaciones sociales aquéllos son extremadamente vallosos ya que incluso pueden recoger términos que no han sido documentados en la literatura clásica. Hay que tener en cuenta que la especialización del trabajo no sería tan estricta como una visión actual de los procesos industriales de fabricación nos podía sugerir. Diversos términos pudieron de facto corresponder a individuos que realizaran una misma actividad, especialmente si se trataba de talleres menores; es probable que la división de las tareas y funciones fuera más acusada en las grandes canteras y officinae.

Estos artesanos eran de diversa condición social ${ }^{24}$. Entre los que trabajaban directamente en las canteras, es decir, llevando a cabo los trabajos más duros, habría un importante porcentaje de población esclava; entre ellos podria incluirse a los llamados damnati a metalla, término este último que, según Cisneros Cunchillos $(1988,260)$, incluía tanto a las explotaciones mineras como a las de extracción de piedra.

${ }^{22}$ Es decir, todo aquel material susceptible de ser pulido y de ofrecer un acabado liso.

${ }^{23}$ La diferencia entre ambos parece también estribar en el material de sorporte empleado. Con respecto a esta distinción entre marmor y lapis, Lapuente. Cisneros y Origa $(1988,258)$ senalan que el último de ellos. a pesar de designaz a las rocas en general. era acompañado de un calificativo que especificaba su variedad. Asi documentamos en diversas inscripciones lapis lunerasts, tiburtinus, o incluso lapis sicili marmoratus (CIL III. 14120) Además de éstos, existían también otras expresiones que se acuñaron con el fin de indicar tareas especiales, como sculptor, quadratarius o sigillareus.

${ }^{24}$ Son escasas las referencias sobre la condición social y la situación en la que vivia este tipo de artesanos dedicados al trabajo de la piedra en sus diversas fases. No obstante, y más referido a los sculptores, véase: Blázquez. 1994; Sánchez, Luján y Trillmichn, 1992. 
Siguiendo a Dodge $(1988,72)$ y a Ward Perkins (1980; 1992) sabemos que en las canteras había trabajadores especializados que conocian las técnicas a emplear en la extracción del material correspondiente y que incluso podian trasladarse con él a sus lugares de destino (RECASENS, 1987, 124) Estos especialistas llevaban a cabo la obtención de los bloques de piedra asi como la preparación de las piezas, en sus diferentes fases, para su exportación. En algunos casos como en ciertas canteras de Frigia, las piezas habrian sido allí prácticamente finalizadas. No obstante esto será más propio de momentos tardíos en los cuales el complejo sistema de mercado extendido por todo el Imperio se había ya debilitado, limitándose a abastecer mercados locales.

Las relaciones jurídicas y económicas entre los artesanos que trabajaban en las canteras y la administración de las mismas es también un tema hasta el momento poco conocido. Pudieron quizá depender directamente de ella (ratio patrimonii imperialis) u organizarse en collegia (SANTERO, 1978, 126-127) tratando de conservar cierta independencia en sus actividades.

\section{Las escuelas}

Señala P Pensabene $(1972,318)$ la dificultad para poder precisar la existencia de talleres itinerantes. si bien contamos con ejemplos documentados como puedan ser algunos de los dependientes de la ya citada Afrodisias. Aquéllos procedían de escuelas creadas, o bien en las propias canteras, propiciadas por las características de un material determinado, o bien en los centros de más intensa y continuada actividad edilicia. Se trasladarian a los lugares donde un nuevo edificio o todo un nuevo programa monumentalizador precisara de sus servicios. No será fácil aislar los elementos estilísticos que puedan con seguridad identificar a una escuela determinada. Esto se debe principalmente al influjo que sobre ella ejercian las tradiciones locales así como el uso de modelos de diversa procedencia.

La investigación debe ser cautelosa con los métodos tradicionales empleados basados en cuestiones estilisticas. Encontrar elementos de una misma tipología que procedan de lugares alejados geográficamente, puede responder a diversos mecanismos: talleres transferidos, modelos imitados por talleres locales, productos importados. Incluso la procedencia del mármol no es un elemento tan decisivo como podría pensarse si tenemos en cuenta el papel aglutinador de materiales que ejercieron algunas ciudades como por ejemplo la propia Roma, dándose por hecho la existencia de este tipo de centros también para áreas locales ${ }^{25}$.

${ }^{25}$ A pesar de ello, es interesante esta afirmación de M. Mayer $(1994,513)$ : " Resulta, no obstante, indispensable pensar que los contactos artisticos están vinculados, en el caso de los materiales arquitectónicos decorativos, a los soportes sobre los que se tallan y que la circulación de modelos está vinculada también muchas veces a la de materiales. 
En su análisis de los talleres presentes en la Península ibérica, P Pensabene (1993, $298,302)$, reconoce diversos grados de intervención más allá de la clasificación tradicional en talleres locales y urbanos:

1) Directamente ligados a Roma e incluso procedentes de ella.

2) Itinerantes; probablemente italianos y activos en la propia Italia y en las provincias occidentales en proyectos de arquitectura oficial. Utilizan modelos inspirados en la capital pero respecto a ellos aportan modificaciones adquiridas en el curso de su actividad lo que permite distinguir su estilo del de la Urbs.

3) Locales con un ámbito de actividad local y en ocasiones interprovincial, empleados siempre en proyectos monumentales de arquitectura oficial con el uso tanto de mármoles importados como de otras piedras locales. Conocen los modelos de Roma.

4) Locales empleados en los monumentos oficiales de la ciudad; utilizan fundamentalmente piedras locales y siguen tradiciones decorativas relacionadas con la propia ciudad y no directamente vinculadas con los modelos contemporáneos al uso en Roma.

En las ciudades o en sus proximidades era frecuente que se establecieran talleres ocasionales con motivo de una construcción puntual. Normalmente dependian de otros estables pero tampoco se descarta el hecho de que una obra de mayor envergadura tanto en el espacio como en el tiempo precisara de la transformación de estos canteros temporalmente desplazados en oficinas independientes.

\section{Letras y signos: testimonio de la presencia de artesanos y escuelas}

Del mismo modo, han podido documentarse tanto sobre bloques de piedra en bruto como sobre elementos arquitectónicos semielaborados o incluso finalizados, toda una serie de inscripciones ${ }^{26}$ asociadas a la actividad desarrollada por estos operarios, dentro de las diversas fases de trabajo en las que intervenían. Trabajos ya clásicos como los de Bruzza (1870) o Dubois (1908) se encargaron de la identificación de muchos de estos epígrafes que, no obstante, continúan siendo objeto de trabajos más recientes (DODGE, 1988. PENSABENE, 1995)

${ }^{26} \mathrm{Si}$ bten las inscritas son las mejor conservadas existen evidencias de tituli picti (DODGE. 1988, 69) asi como de sellos de plomo, que constituian una marca oficial que inciuia la efigie del emperador (BACCNi. 1979, lam. III: Di STEFANO, 1987, 64). 
Estas inscripciones, que pueden ser halladas tanto en los lugares de extracción como en los de destino, aportan una muy valiosa información. En ellas puede figurar (BRUZZA, 1870; Di STEFANO, 1987, 50):

1. Nümero de orden del bloque

2. Número del locus o bracchium, es decir, el sector de extracción.

3. Nombre del responsable de la caesura.

4. Nombre de la oficina de producción

5. Datación consular (año de producción).

6. Referencia a la ratio urbica (administración central).

7. Nombre del curator, funcionario administrativo encargado del registro.

Los bloques solían salir de la cantera perfilados con forma aproximadamente paralelepipédica con el fin de facilitar su transporte. En esta fase la información que se añadía sobre ellos era de tipo burocrático-administrativo.

Las fórmulas variaban según las canteras, de igual forma que no en todas ellas se emplearon ${ }^{27}$, a ello debe unirse el que se hayan conservado en un muy escaso porcentaje, ya que en muchos casos se habrían realizado con minio y, por tanto, se eliminaban al ser trabajada la pieza. H. Dodge $(1988,70)$ añade que ésta habria sido además una práctica restringida aproximadamente al periodo entre los gobiernos de Nerón y Septimio Severo.

Como sugirió L. Bruzza (1870, 106-107), los bloques de piedra en bruto también habrian sido objeto de marcas en los almacenes encargados de la distribución, como puedan ser los de Roma ${ }^{28}$, por él estudiados. En ellas se hacia referencia principalmente al destino de los materiales, ya que, en la mayor parte de los casos, se trataba de partidas que debian ser embarcadas para ser transportadas por mar a otros puntos del Imperio. en ocasiones muy alejados.

En el lugar de destino podían adquirir nuevas siglas para ser almacenados. Lo más frecuente para este tipo de marca de producción era officina o ex officina seguido de la onomástica de un individuo en genitivo (ya fuera tan sólo su cognomen o los tria nomina). La officina era el lugar donde trabajaban los artifices, no obstante, este término parece haber hecho referencia a todo el ámbito de producción, incluyendo por tanto también a los centros redistribuidores de productos de áreas más amplias.

P. Pensabene ha sugerido, a partir del estudio de capiteles procedentes de Ostia y Leptis Magna, que, en ocasiones, los operarios harian constar su nombre, la abreviatura

${ }^{27}$ Se conservan marcas en las canteras de Luni, Chios, Paros, Scyros, Docimium. Cherntou, Carysios, Teos, Proconeso y en las egipcias del Mons Porphyrites.

${ }^{28}$ El llamado Emporium del Aventino (Marmorata), almacenes creados en el 193 a.C. ante el crecimiento de la ciudad y la imposibilidad de ampliación del antiguo puerto, en el área del Foro Boario. 
Por último, algunas de las inscripciones encontradas sobre elementos no corresponden ni a marcas de cantero ni de oficina, pudiendo tratarse de lo que J. P Adam $\left({ }^{4} 1996,54\right)$ ha denominado indices de posicionamiento, encargadas de señalar el lugar de ubicación de cada pieza dentro del conjunto, ya que, en su gran mayoría éstas no podrían colocarse de forma aleatoria.

Tres fragmentos de fuste del teatro italicense presentan pares de caracteres griegos $^{29}$ Sobre dos de ellos, en el plano de su imoscapo y de su sumoscapo respectivamente. se han inscrito las letras griegas $\Theta E^{30}$. Lo más probable es que se trate de numerales. No obstante, otras hipótesis sugeridas por la repetición de marcas pueden ser la ya citada de identificar las piezas realizadas por un operario, o incluso, tras analizar las medidas de ambas, la de señalar el ya citado indice de posicionamiento, haciéndolas corresponder en una misma vertical en la columnatio de la scaenae frons (fig. 15, a y b). En el tercero de ellos, un fragmento de fuste liso de columna en mármol blanco rosado, se han reconocido, no sin dificultad, debido a la irregularidad de la superficie, las letras A $\Omega$. Se sitúan sobre el plano de su imoscapo, siendo el segundo de los caracteres de menor tamaño que el primero (fig. 15, c). Formaría también parte del orden superior de la scaenae frons.

Estas letras griegas podrían ponerse además en relación con trabajadores orientales encargados en el edificio del programa decorativo del siglo III d.C., y que pudieron trasladarse en este momento junto con el abundante mármol euboico de Karystos ${ }^{31}$ empleado en dicha reforma.

\section{LAS HERRAMIENTAS. EL INSTRUMENTAL}

Como bien señaló Ward Perkins (1992a, 17; 1992b, 23), no eran muchos los recursos técnicos con los que se contaba en la antigüedad para la extracción de piedra en las canteras. Como cierto avance sugiere, a partir del siglo III d.C., el empleo de la sierra pendular en el propio frente de cantera para la extracción de bloques y no tan sólo para el serrado de piezas ya exentas como se habia hecho hasta entonces. No obstante algo fundamental fue la introducción del instrumental de hierro en cantería. La conquista de Egipto supuso para el mundo romano no solamente el acceso a sus valiosas canteras de granito, sino también a sus sistemas de administración, así como a las técnicas de extracción y transporte desarrolladas en ellas (ORTOLANI, 1989, 20-25).

${ }^{29}$ Uno de ellos, el reproducido en la fig. 15, a, ha sido reintegrado durante las labores de restauración del edificio a su scaenae frons, por lo que no ha podido ser analizado personalmente por nosotros. limitándonos a incluir el dibujo que en su dia presentó $\mathrm{E}$. Conde (1994, 127, fig. 6).

${ }^{30}$ En uno de elios. fig. 15, a, no se aprecia el brazo superior de la épsilon.

31 También en Leptis Magna se han documentado en la base de algunos capiteles los nombres abreviados o por extenso en griego de los que han sido identificados como sus artifices. Estas marcas se asocian a la presencia de operarios de la escuela de Afrodisias en la ciudad y al auge de los modelos orientales. 
del mismo o alguna marca que los identificara sobre las piezas realizadas, a fin de facilitar el posterior recuento y el consiguiente pago de los ejemplares ejecutados.

Es posible que a ello respondieran tres ejemplos documentados solre fustes en el teatro romano de Itálica. El primero de ellos, realizado en mármol cipollino, e identificado como del orden superior de la scaencie frons, se trata de un fragmento correspondiente al sector de su sumoscapo moldurado. En su plano superior, en torno a un orificio central con canal lateral, posee la inscripción LV EMILI / SE NS, en dos líneas horizontales (fig. 14, a). En un segundo fragmento de fuste liso, en esta ocasión cle su mitad inferior, con imoscapo resaltado, se ha inscrito en su plano inferior, de nuevo distribuido en torno a una cavidad cuadrangular central, el siguiente epígrafe: PIP / PCV. La dirección de escritura de ambas líneas es perpendicular entre sí. La pieza está realizada en mármol blanco y se adscribe a los órdenes de módulo menor que formaron parte de la decoración del frente de la escena (fig. 14, b). Un último ejemplo, en mármol blanco rosado, en el plano de su imoscapo presenta las letras QCF, realizadas de forma muy tosca, como puede apreciarse en la figura 14, c.

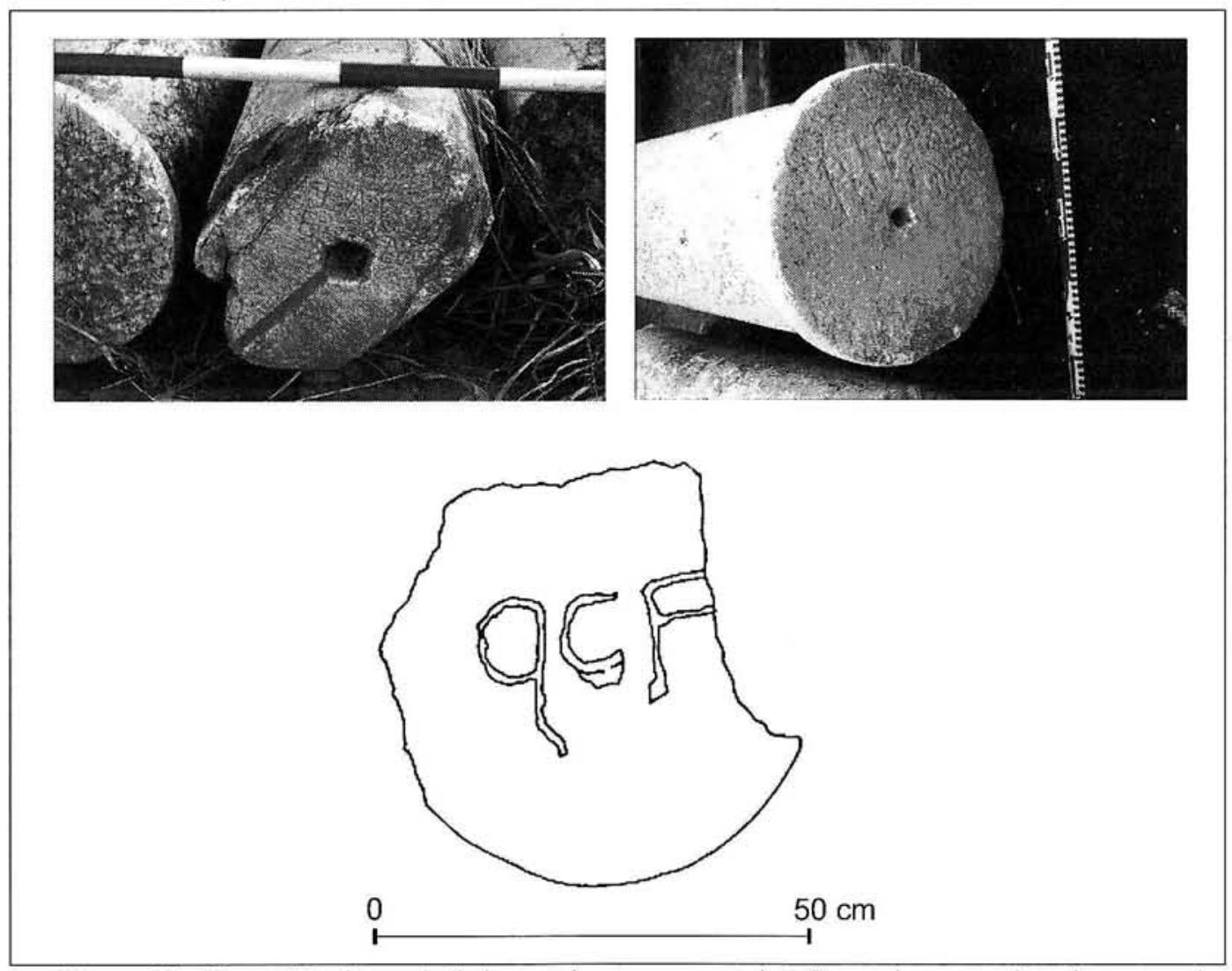

Figura 14.-Fustes de columna hallados en el teatro romano de Itálica en los que se han documentado caracteres latinos incisos 


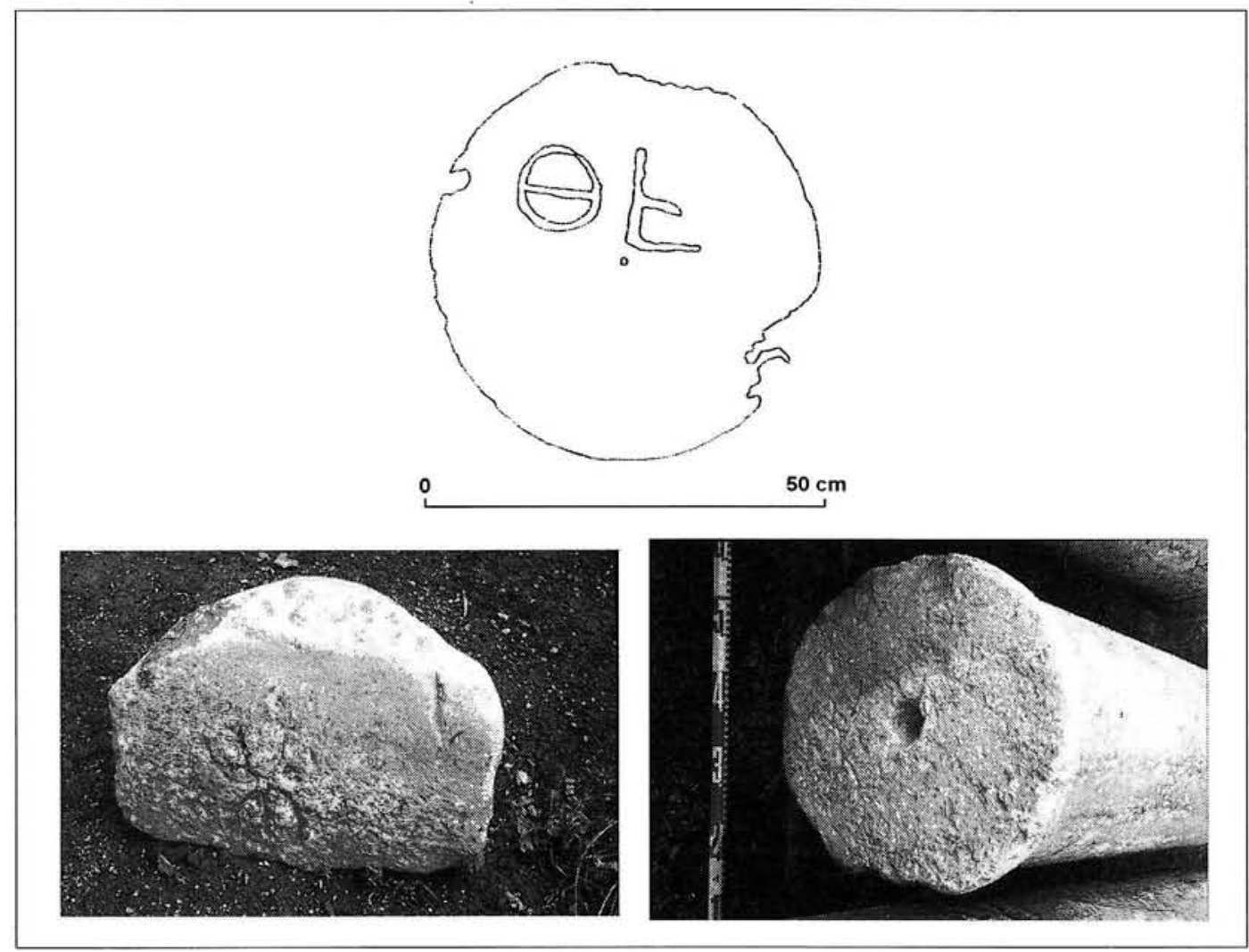

Figura 15. - Fustes de columna hallados en el teatro romano de Itálica en los que se han documentado caracteres griegos incisos

Al margen de lo anterior resultan de gran interés las reflexiones que ya hizo el mismo autor con respecto a la tecnología y a la fuerza de trabajo en época antigua. En este momento los avances tecnológicos serían limitados, sin embargo evolucionó la capacidad y la habilidad para usar dicha tecnología (WARI) PrRKINS, 1992a, 18).

Para el conocimiento del instrumental empleado en época romana para el trabajo de la piedra, en especial para la elaboración de elementos arquitectónicos, la investigación se ha valido de tres elementos. Por un lado de los útiles tradicionalmente empleados en cantería y que han permanecido casi inmutables hasta nuestros días (ORTOL.aNi, 1989), $19)^{32}$; por otro, del registro arqueológico, que además de proporcionarnos los utensi$\operatorname{lios}^{33}$, nos ha permitido comprobar la citada continuidad en el tiempo de las herramientas y de las técnicas que estas suponen. Por último, aparecen en un buen número de representaciones gráficas, en la mayor parte de los casos en contextos funerarios de in-

\footnotetext{
32 Véasce Ginouvés y Martín, 1985. 1.I, fig. 6. Reproducimos en la figura 16 algunas de estas herramientas.

33 In buen ejemplo de ello en Ponte. 1974.
} 
dividuos que las emplearon en su trabajo diario y que quisieron también tenerlas presentes en su propia tumba ${ }^{34}$ Estas últimas son especialmente valiosas ya que en el registro arqueológico no se han conservado las piezas y elementos realizados en materiales perecederos como madera, que sería muy abundante.

A pesar de los trabajos realizados (LUGLi, 1957; GINOUVÉS y MARTIN, 1985; DI STEFANO, 1987: BRUTO y VANNICOLA, 1990), existe todavía cierta confusión terminológica en lo que se refiere, primero, a la identificación de los nombres dados a las diversas herramientas en la antigüedad, después, a la correspondencia entre éstos y los que poseen en nuestros días. No ha contribuido a clarificar la situación el que, especialmente en lo referido a este tipo de instrumental de empleo ininterumpido en el tiempo desde época antigua y generalizado geográficamente, sean abundantes las variantes regionales, dialectales, etc.

Para ilustrar las observaciones anteriores y a modo de anexo, hemos creido oportuno incluir un conciso listado que recoge los principales utensilios empleados en el trabajo de la piedra y más concretamente en la fabricación de elementos arquitectónicos (fig. 16). Del mismo modo, aportamos una serie de ejemplos gráicos, de nuevo de elementos arquitectónicos procedentes del teatro romano de Itálica, en los que pueden observarse las diversas marcas dejadas por el empleo de algunas de estas herramientas (fig. 17) (BESSAC, 1988; PENSABENE, 1995, 349-352)

- Bujarda. (fig. 16, a) Se incluyen dentro de esta denominación dos variantes de cincel y martillo. El primero de eilos, también conocido como cincel grano de cebada (BESSAC, 1988, 47, fig. 12) presenta una hoja rectilínea dentada; otra variante sería la gradina, cuyos dientes estaban curvados a modo de pequeños garfios. El segundo, llamado también martillo gradillado, ofrecía un frente de percusión a base de pequeñas puntas piramidales. Todos ellos se empleaban para retallar las superficies pétreas. Eran más eficaces con rocas blandas. La huella de trabajo consistía en surcos paralelos (KOZEIL, 1988b).

- Cuneus (cuña): (fig. 16, b) realizado en metal o madera, se empleaba para cortar la roca.

- Dolabra: (fig. 16, c) es un martillo de talla, a modo de un hacha de dos filos.

- Lima: (fig. 16, d) presenta una superficie a base de minúsculas protuberancias apuntadas utilizada para desgastar las superficies y/o eliminar sus imperfecciones o irregularidades.

- Malleus (mazo, maza): (fig. 16, e) podia estar realizado en hierro o madera, en este último material, más blando, era empleado en labores de acabado de las piezas. También se usaba para introducir las cuñas en el perimetro de los bloques en las labores de extracción.

${ }^{34}$ En el clásico de G. Lugli (1957. 221-223) se incluyen algunos de los ejemplos más ilustrativos como puedan ser el frontón de una edícula funeraria en el Cementerio de Pretestato en Roma (1957. 222, n. ${ }^{\circ}$, lám. XXV, 1), o un cipo funerario del Museo Capitolino de la misma ciudad (1957. 222. n. 4, 1am. XXV, 4) 


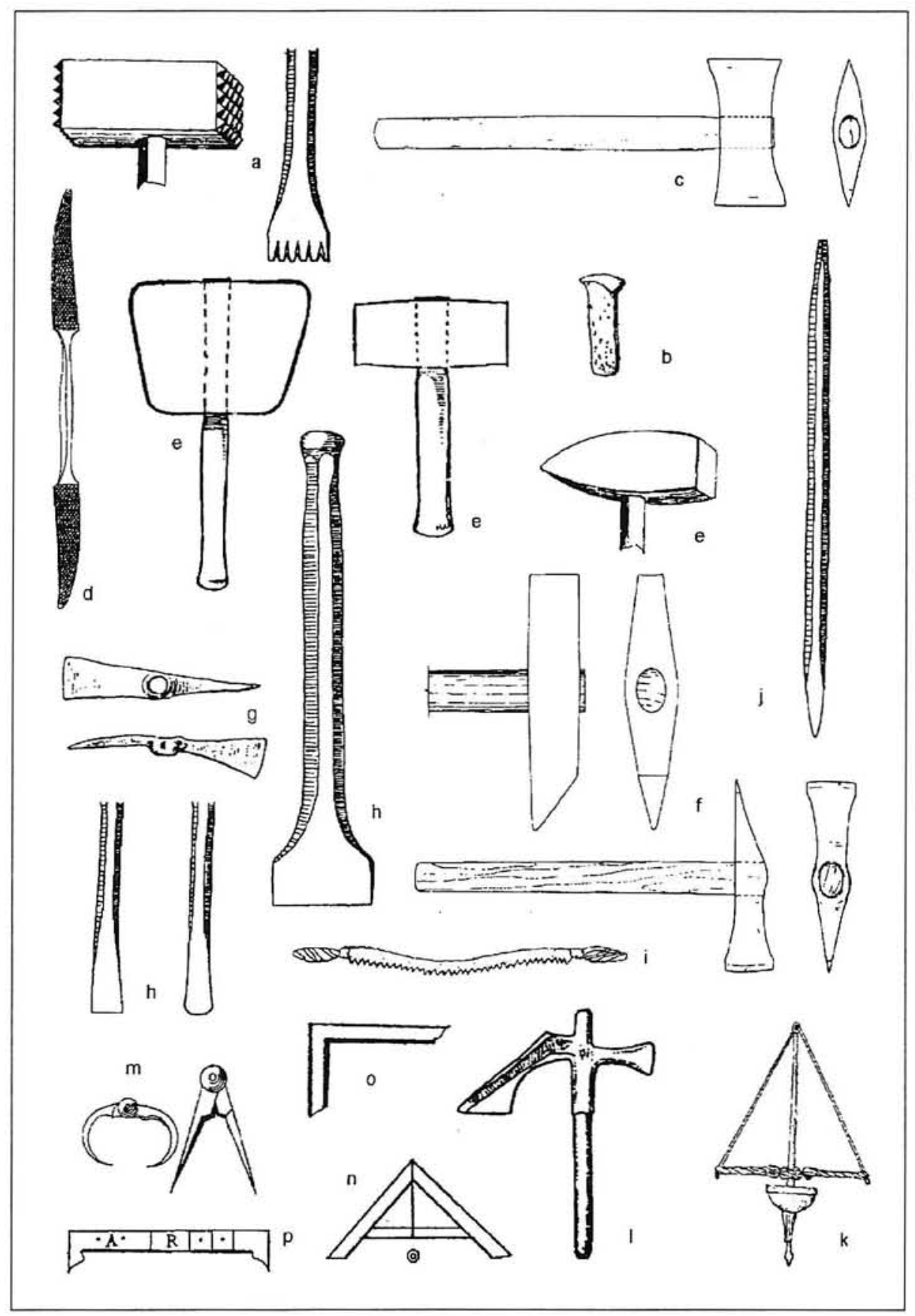

Figura 16.-Algunos de los principales instrumentos empleados en la fabricación de elementos arquitectónicos en época antigua. (A partir de Ginouvés y Martín, 1985, fig. 6; Di Stefano, 1987, 256 y Pensabene, 1995, figs. 365 y 366) 


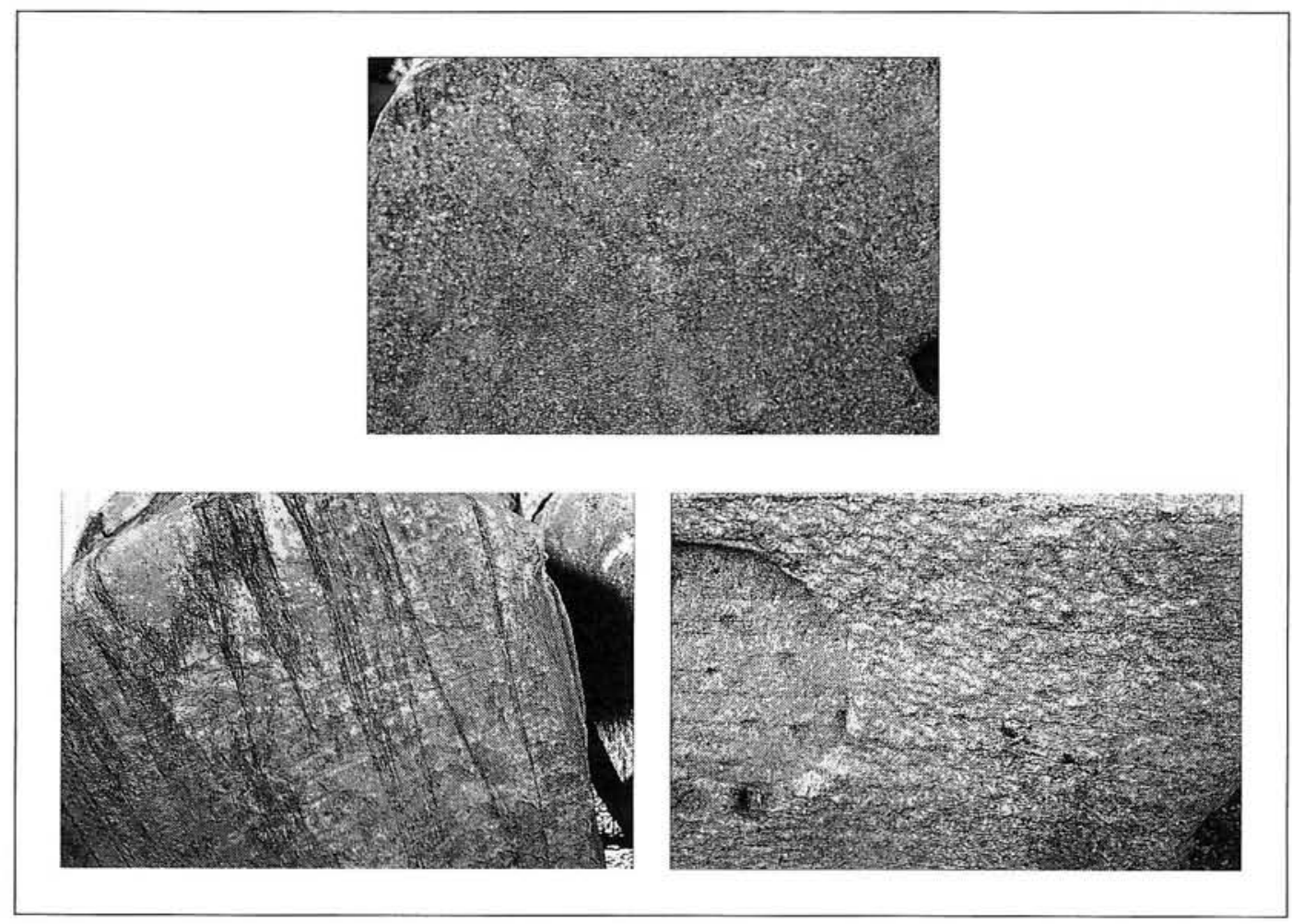

Figura 17.-Algunos ejemplos de las marcas de cliversals herramientas al ser empleadas en la elaboración de clementos arquitectónices

- Malleolus (martillo): (fig. 16, f) su menor tamaño y poco peso hacía de él un instrumento idóneo para, con ayuda de un cincel intermedio, llevar a cabo un desbastado controlado de la piedra.

- Materiales abrasivos, arena: se utilizalan en las últimas fases, de acabado de las piezas.

- Polka: (fig. 16, g) es nuestra piqueta actual, es decir un instrumento de dos filos perpendiculares: uno vertical y otro horizontal. Debió de ser un utensilio muy apreciado para el trabajo de la piedra, especialmente de las blandas, en sus diversas fases, ya que permitía abordar el tallado de las piezas desde múltiples ángulos.

- Scalprum (escalpelo, cincel): (fig. 16, h) de hoja cortante, se golpea con el mazo en su extremo opuesto, romo. Se empleaba tanto en las labores de cortado como para tallar y esculpir.

- Serra (sierra): (fig. 16, i) solía ser de hoja recta, no dentada. Se mantenía rígicla entre los extremos de un armazón de madera en el cual se desplazaba. Para aumentar su efectividad el operario se ayudaba de arena y agua, ésta última para evitar el solorecalentamiento producido por el rozamiento. Para el serrado de grandes piezas también se emplearon sierras de gran tamaño que se movían valiéndose de un sistema de péndulos. 


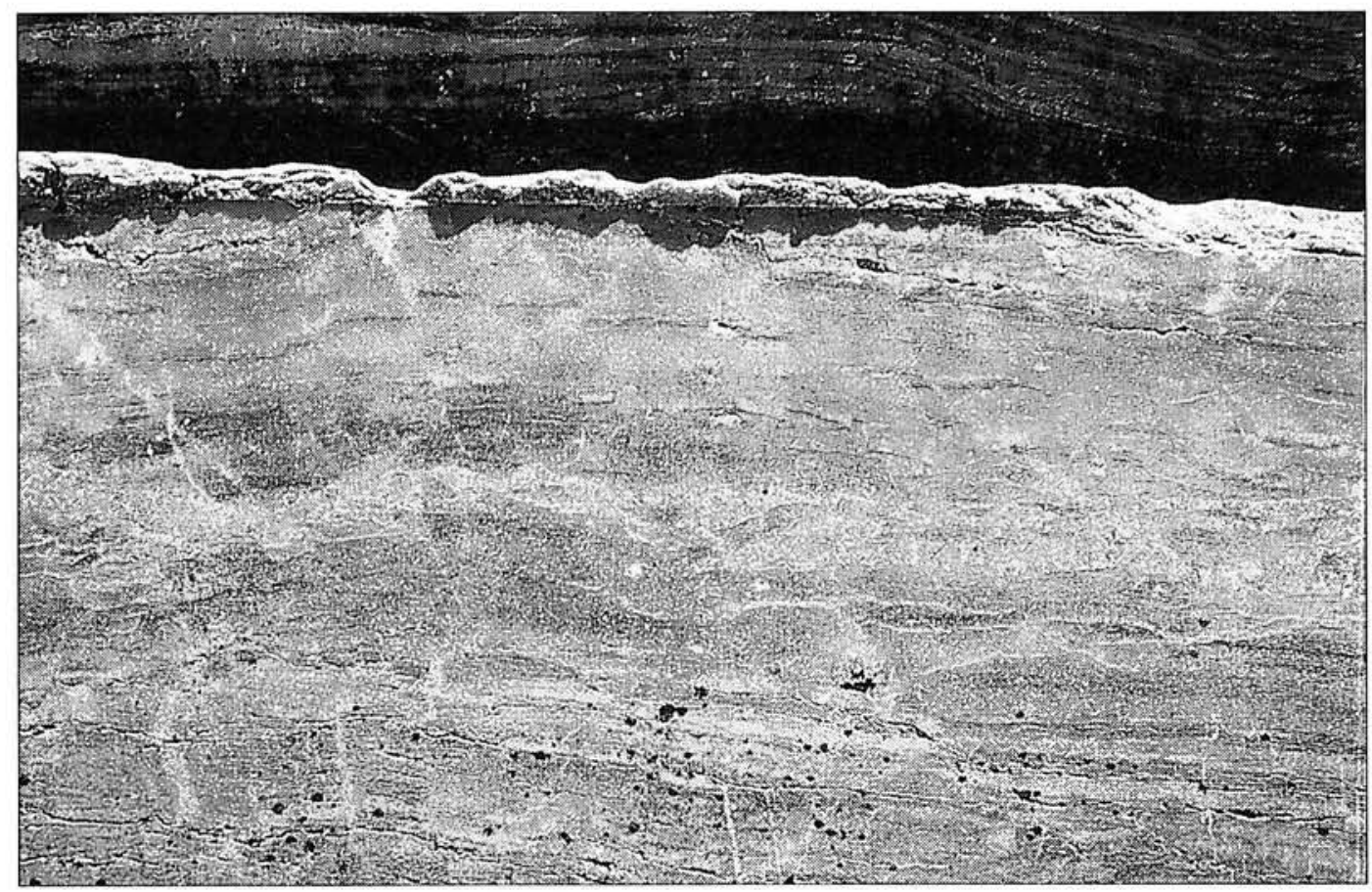

Figura 18. - Fragmento de fuste de columna en el que se aprecia la línea irregular de rotura dejada tras el serrado de la pieza

- Subula (gubia): (fig. 16, j) clavo de hierro a modo de aguja, de punta piramiclal (D) STEFANO, 1987, 116). Parece haberse denominado también así a un cincel de sección curva (Bessac, 1988, 48). Las huellas de trabajo que dejaba su empleo sobre la piedra dependían del grado de inclinación con el que se aplicara (PENSABENE, 1995, 352, fig. 367).

- Terehra (trépano): (fig. 16, k) consistía en una punta que giraba sobre sí misma, propulsada por un sistema consistente en un arco de madera y una cuerda sujeta a sus extremos. Existirían diferentes tipos de puntas según las necesidades de la labor a realizar.

- Tornus (torno): proporcionando un movimiento circular a piezas cilíndricas, permitía trazar sobre ellas molduras a lo largo de toda su longitud (perímetro) (PRECHT, 1990).

- Ipupa (pico): (fig. 16, 1) se usaba en diversos trabajos, desde en la cantería propiamente dicha hasta en carpintería y allbañilería. Según I. cli Stefano Manzella dentro de sus variedades podría incluirse el pico actual así como la piqueta menor, más ligera y de trabajo más ágil. Se emplearía en el trabajo de cantera y al deshastar los bloques hasta conseguir un volumen aproximado de lo que sería la pieza clefinitiva. La huella que cleja su empleo es muy característica: un piqueteaclo rugoso. 
- Circinus (compás): (fig. 16, m) existían dos tipos. Uno de brazos curvos empleado para tomar diámetros internos y espesores, que suponemos especialmente útil para la realización de la decoración de los capiteles, y otro de brazos rectos para medir distancias, hallar puntos equidistantes, bisectrices, etc.

- Livella (nivel): (fig. 16, n) empleado para medir el grado de inclinación de un plano. consistía en dos brazos que se cortaban en ángulo recto. Sobre un tirante graduado horizontal que unia ambos se hacia pasar una cuerda que partía del vértice del ángulo y se remataba en un peso (plomada).

- Norma (escuadra): (fig. 16, o) instrumento en forma de L, servia para trazar ifneas perpendiculares entre sí. Las había también de brazos articulados.

- Perpendiculum (plomada): empleado para proporcionar líneas verticales de referencia. Era de forma cónica.

- Regula (regla): (fig. 16, p) listón graduado, cuyas medidas correspondían a submúltiplos del pie romano. Podía realizarse en madera con los extremos metálicos, pero lo más frecuente era de una sola pieza en bronce.

\section{CONCLUSIONES}

No parece haber existido uniformidad en lo que se refiere al proceso de fabricación de los elementos arquitectónicos. Así lo dejaban ver trabajos ya clásicos como los de F. Corsi (1833) o Ch. Dubois (1908). En los últimos años, especialmente P. Pensabene ha documentado cómo según las canteras, el tipo de piezas, etc., éstas podian ser esbozadas en aquéllas o realizadas directamente en los talleres próximos al lugar de construcción del edificio para el que estaban destinadas.

A pesar de esta falta de regularidad, lo que si es cierto es que se pueden reconocer y sistematizar toda una serie de marcas, huellas de grapas, y signos que, formando ya parte de las prácticas de construcción en época griega, se difundieron en todo el Imperio romano, pudiendo hablar de un fenómeno generalizado aunque presente las numerosas variantes locales propias de unas prácticas meramente pragmáticas, en las que cada operario o su colectivo se dejaba guiar por la tradición o por las ventajas que unos sistemas suponian sobre otros dentro de los diversos procesos.

Hemos propuesto aquí algunas cuestiones generales, otras, no lo son tanto y se refieren a ejemplos bien conocidos que pueden servir de modelos mientras se encuentran nuevos datos arqueológicos que permitan la reconstrucción de procesos completos como Ios observados en las canteras del Proconeso, el pórtico del Coliseo o las columnas del templo de Adriano en Roma.

La falta de sistematización impedirá que muchos de estos elementos nos sirvan de valiosos indices geográficos o cronológicos, no obstante, se reconoce la importancia de determinados centros aglutinadores de materiales que posteriormente los redistribuian a 
centros menores, asi como, en una fase posterior, las identificación de escuelas o determinadas tendencias decorativas.

Hemos querido recurrir, para demostrar no obstante, la realidad de los procesos y técnicas descritas, al ejemplo de un conjunto cerrado de elementos arquitectónicos como son los procedentes del teatro romano de Itálica. En ellos han podido constatarse todos y cada uno de los elementos analizados, ya sean líneas guía para la fabricación de las piezas, o cavidades, espigas y mortajas para grapas y pernos adoptando diversas variantes como auxilio en sus procesos de transporte, elevación y ensamblaje. Todo ello nos debe llevar a valorar la complejidad de una construcción como pueda ser este edificio italicense, complejo pero también por ello muy bien organizado para que todas y cada una de sus piezas encajaran sin sorpresas de última hora. Esto obligaba a que se emplearan unas normas sistemáticas en la fabricación de piezas, regidas por estrictos cálculos geométricos, puestos de manifiesto tanto en basas como también en fustes y capiteles. Es además muy posible que existieran códigos que les permitieran en todo momento identificar la posición en la que deberian ubicarse todas y cada una de las piezas, ya que, en la mayoría de los casos, ésta no podía ser intercambiable. Muchas de estas marcas se borraron con el paso del tiempo, o incluso fueron eliminadas intencionadamente una vez que perdieron su utilidad, no obstante, algunas de ellas han llegado hasta nosotros. en forma de caracteres grabados sobre los planos de apoyo de determinados fustes. También estas huellas deben ser puestas en relación con los operarios y talleres en los que se fabricaban los elementos arquitectónicos. Aquí es necesario recordar la compleja cuestión de identificar el origen de los elementos y sus creadores, siendo para ello fundamental caracterizar los grados de acabado a los que se llegaba en las canteras y el estado en el que las piezas eran exportadas. Del mismo modo valorar la movilidad de los talleres y artesanos, así como de las tendencias decorativas. Algunos caracteres griegos presentes en fustes del teatro de Itálica parecen poder sugerir la presencia de trabajadores orientales, que, muy posiblemente habrian viajado junto a materiales de su mismo origen, de los cuales eran expertos conocedores.

\section{BIBLIOGRAFIA}

ADAM, J P. ( $\left.\left.{ }^{4} 1996\right)\right)$ : L'arte di costruire presso i romani. Materiali e tecniche, Milán.

ASCARI, N. (1988): "The stages of workmanship of the Corinthian capital from Proconnesus and its export form". HERZ, N. y WAELKENS, M.: Classical Marble: Geochemis. try, Technology, Trade, Lucca 1988, Dordrecht, 115-125.

- (1990): "Objects de marbre finis, semi-finis et inacheves du Proconnese", en WAELKENS, M. (ed.): Pierre eternelle. Du Nil au Rhin, carrières et fabrication, Bruselas, 106-126.

- (1992): "Observations on two types of quarry-items from Proconneus: column-shafts and column-bases", en WAELKENS, M.; HERZ, N., y MOENS, L. (Eds.): Ancient Stones: 
Quarrying. Trade and Provenance. Interdisciplinary Studies on Stones and Stone Technology in Europe and Near East from the Prehistoric to the Early Christian Period, Lovaina, 73-80.

BACCINI LEOTARDI, P (1979): Marmi di cava rinvenuti ad Ostia e considerazionl sul commercio dei marmi in età romana, Scavi di Ostia, X, Roma.

BARRERA, J. L. de la (1984)' Los capiteles romanos de Mérida, Monografias Emeritenses, 2 , Badajoz.

BELLONI, G. C. (1958): I capitelli romani di Milano, Padua.

BESSAC, J. C. (1988): "Problems of identification and interpretation of tool marks on ancient marbles and decorative stones", en HERZ, N. y WAELKENS, M.: Classical Marble: Geochemistry. Technology, Trade, Dordrecht, 41-53.

BEYKAN. M. (1988) "The marble architectural elements in export-form from the Sile Shipwreck", en HERZ, N., y WAELKENS, M.: Classical Marble: Geochemistry, Technology, Trade, Dordrecht, 127-137.

BLAZQUEZ, J. M. " (1994). "La situación de los artistas y artesanos en Grecia y Roma", en Artistas y artesanos en la antigüedad clásica, Cuadernos Emeritenses, 8, Mérida, 10-28.

BRUTO, M. L., y VANNICOLA, C. (1990): "Strumenti e tecniche di lavorazione dei marmi antichi", Archeologia Classica. XLII, 287-324.

BRUZZA. L. (1870): "Iscrizioni dei marmi grezzi", Annali dell'stituto di Corrispondenza Archeologica, 42, 106-204.

CALABI LIMENTANI, J (1958): Studi sulla società romana. I/ lavoro artistico, Milano-Varese.

Cisneros Cunchilios, M. (1988)' "Consideraciones metodológicas para el estudio de las canteras de mármol en Hispania a partir de un texto de Plinio (NHIII, 3.30)", Actas del I Congreso Peninsular de Historia Antigua, Santiago de Compostela 1986, Santiago de Compostela, 259-264.

ClARIDGE, A. (1983): "Methods of fluting corinthian columns and pilasters". Città e Architettura nella Roma Imperiale", Atti del Seminario del 27 ottobre 1981 nel 25. anniversario dell'Accademia di Danimarca, 119-128.

CONDE LEON, E. (1994): "Dibujos geométricos en el teatro romano de Itálica", Revista de Expresión Gráfica Arquitectónica, 2, Valladolid, 125-128.

CORSI, F. (1833): Delle pietre antiche, trattato di Faustino Corsi romano: ed. seconda in alcune parti corretta in molte accresciuta, con l'aggiunta dell'indicazione e descri. zione di tutte le colonne ragguardevoli e massi di pietre antiche che sono a Roma, Roma.

DIAZ MARTOS, A. (1985): Capiteles corintios romanos de Hispania. Estudio-catálogo, Madrid.

Di SteFano ManZelia. 1. (1987): Mestiere di epigrafista. Guida alla schedatura del materiale epigrafico lapideo, Roma. 
DODGE, H. (1988): "Decorative Stones for Architecture in the Roman Empire", Oxford Journal of Archaeology, 7, n. ${ }^{0} 1,65-80$.

DOLCI, E. (1989): "Il marmo nel mondo romano: note sulla produzione e il commercio". en DOLCI, E. (ed.). Il marmo nella civiltà romana. La produzione e il commercio, Lucca, 11-53.

DuBOIs, Ch. (1908): Etude sur l'administration et l'exploitation des carrières -marbles, porphyre, granit, etc.- dans le monde romaine, Paris.

DURÁN, R. (1991-92): "Técnicas de edilicia romana en Mérida", Anas, 4-5, 45-80.

GINOUVES, R., y MARTIN, R. (1985): Dictionaire méthodique de l'architecture grecque et romaine, Roma.

GIULIANI, C.F., (51997) L'edilizia nell'antichità, Roma.

GUTiłrReZ BeHEMERID, M.A. (1992): Capiteles romanos de la Peninsula ibérica, Valladolid.

HEILMEYER, W. D. (1970). Korintische Normalkapitelle. Studien zur Geschichte der römischen Architekturdekoration, Mitteilungen des Deutschen Archäologischen Instituts. Römische Abteilung, suppl. 16, Heidelberg.

Jiménez Martí, A. (1982) "Teatro de Itálica. Primera campaña de obras", Itálica (Santiponce, Sevilla), E.A.E., 121, Madrid, 277-290.

- (1983). "Notas sobre un dibujo romano", Cuadernos de Construccion, 6, Sevilla, 1822.

- (1989): "Las columnas del Teatro de Itálica", Homenaje al profesor Antonio Blanco Freijeiro, Madrid, 277-318.

JimÉneZ MARTIN, A.; MONTERo FERnÁNDEZ, F J., y RODRíGueZ PÉREZ, P. (1991-92): "El temblor de la falsificación", Periferia, 11, Sevilia, 36-53.

KÄHLER, H. (1939): "Die Römischen Kapitelle des Rheingebietes", Romischgermanische Forschungen, 13, Berlín.

KAPITÄN, G. (1971): "Explorazioni su aìcuni carichi di marmo e pezzi architettonici davanti alle coste della Sicilia Orientale ${ }^{n}$, Atti $3 .^{\circ}$ Congresso Internazionale di Archeologia Sottomarina, 1961, 296-309.

- (1980): "Elementi architecttonici per una basilica dal relitto navale del VI secolo di Marzamemi (Siracusa)", Corsi di Cultura sull'Arte Ravennate e Bizantina, 27, 71136.

KOZELJ, T. (1988a) "Les carrieres des epoques grecque, romaine et byzantine: tecniques et organization", en FANT, J.C.: Ancient Marble Quarrying and Trade Papers from a Colloquium held at the Annual Meeting of the Archeological Institute of America, San Antonio, Texas, diciembre 1986, B.A.R. Int. Series, 453, Oxford, 3-79.

- (1988b): "Extraction of Blocks in Antiquity: Special Methods of Analysis", en HERZ, N., y WaElkens, M.: Classical Marble. Geochemistry, Technology, Trade, Dordrecht, 31-39. 
LAPUENTE Mercadai, M. ${ }^{2}$ P.; Cisneros Cunchillos, M., y ORTiGa CASTlllo, M. (1988): "Contribución a la identificación de mármoles españoles empleados en la antigüedad. Estudio histórico y petrológico". NAH, 30, 257-274.

LUGL. G. (1957): Tecnica edilizia romana. Con particulare riguardo a Roma e al Lazio, Roma.

MÁrquez, C. (1993): Capiteles romanos de Corduba Colonia Patricia, Córdoba.

- (1996): "Técnicas de talla en la decoración arquitectónica de Colonia Patricia Corduba", L'Africa romana, XII (2), Cartago 1994, Ozieri, 1123-1134.

MAYER, M. (1994): "Los programas decorativos lapídeos de algunas ciudades del África romana y la circulación de algunos materiales africanos", L'Africa romana, Atti del $X$ Convegno di studio, Oristano 1992. Sassari, 503-513.

ORTOLANI, G. (1989): "Lavorazione di pietre e marmo nel mondo antico", en BORGHINI, G : Marmi antichi, Roma, 19-42.

PARKER, A. J. (1992): Ancient Shipwrecks of the Mediterranean and the Roman Provinces, B.A.R. International Series, 580.

PENSABENE, P. (1972): "Considerazioni sul trasporto di manufatti marmorei in età imperiale a Roma e in altri centri occidentali", Dialoghi di Archeologia, VI, 2-3, 317-362.

- (1973): I capitelli. Scavi di Ostia, VII. Roma.

- (1978): "A cargo of marble shipwrecked at Punta Scifo near Crotone (Italy)". The International Journal of Nautical Archaelogy and Underwater Exploration. 7.2, 105-118.

- (1986): "La decorazione architettonica, l'impiego del marmo e l'importazione di manufatti orientali a Roma, in Italia e in Africa (II-VI d.C.) en GIARDINA. A. (a cura di): Società romana e Imperio tardoantico. III. Le merci, gli insediamenti, Roma-Bari, 285-429.

- (1989): "Amministrazione dei marmi e sistema distributivo nel mondo romano", en BORGHINI, G.: Marmi antichi, Roma, 43-53.

- (1992): "The method used for dressing the columns of the Colosseum portico", en WAELKENS, M.; HERZ, N., y MOENS, L. (Eds.): Ancient Stones: Quarrying, Trade and Provenance. Interdisciplinary Studies on Stones and Stone Technology in Europe and Near East from the Prehistoric to the Early Christian Period, Lovaina, 81-89.

- (1993): "La decorazione architettonica dei monumenti provinciali di Tarraco", Els monuments provincials de Tàrraco. Noves aportacions al seu coneixement. Tarragona.

- (1995): Le vie del marmo; i blocchi di cava di Roma e di Ostia. il fenomeno del marmo nella Roma antica, Roma.

- (1996): "Sulla tecnica di lavorazione delle colonne del tempio tetrastilo di Thignica (Aia Tounga)". L'Africa Romana, XII (2), Cartago 1994, Ozieri, 1103-1122.

PONTE, S. (1974): "Ferramentas para trabalhar a madeira", Conimbriga, 13, 45-58.

PRECHT, G. (1990): "Maschinelle Vorfertigung von Säulen und Säulentrommeln", en Bautechnik der Antike, Berlín, 178-183. 
RECASENS I CARRERAS, M. (1987) "Tarraco y el comercio del mármol en época romana a través del estudio de sus capiteles", Pyrenae, 21, 123-128.

RODRIGUEZ GUTIÉRREZ, O. (1998). Introducción al estudio del teatro romano de Itálica: análisis de los elementos de sus órdenes arquitectónicos, Memoria de Licenciatura (inédita). Madrid.

RosSignaNI, J.P. (1975): La decorazione architettonica romana in Parma, Roma.

SÁNCHEZ MORENO, E.; LUJÁN DIAZ, A. M. ${ }^{a}$, y TRILLMICH, W. (1994): "Observaciones en torno al escultor en la sociedad romana. Algunas cuestiones sobre la situación y consideración de los artistas/artesanos romanos", en Artistas y artesanos en la antigüedad clásica, Cuadernos Emeritenses, 8, Mérida, 75-118.

SANTERo SANTURINO. J. M. ${ }^{\text {a }}$ (1978) Asociaciones populares en Hispania romana, Sevilla.

SCRINARI, V (1952): I capitelli romani de Aquileia, Padua.

- (1956): I capitelli romani della Venezia Giulia e dell'Istria. Padua.

WAELKENS, M. (1990): "Technique de carriere, prefaçonnage et ateliers dans les civilizationes classiques (mondes grec et romain)", en WAELKENS, M. (ed.): Pierre eternelle. Du Nil au Rhin, carrières et fabrication, Bruselas, 53-72.

WAElKENS, M., DE PAEPE. P. y MOENS, L. (1988): "Patterns of extraction and production in the white marble quarries of the Mediterranean: History, present problems and prospects", en FANT, J. C. (Ed.): Ancjent Marble Quarrying and Trade. Papers from a Colloquium held at the Annual Meeting of the Archeological Institute of America, San Antonio, Texas, diciembre 1986, B.A.R. Int. Series, 453, Oxford, 81-116.

WaRD PERKinS, J. B. (1980): "Nicomedia and the Marble Trade", Papers of the British School at Rome, 48, 23-69.

- (1992a): "Materials, quarries and Transportation", en DODGE, H., y WARD PERKINS, B. (Eds.): Marble in Antiquity. Colledted Papers of J. B. Ward Perkins, Archaeological Monographs of the British School at Rome, n. ${ }^{\circ}$ 6, cap. IV, 13-22.

- (1992b): "The Roman System in Operation", DODGE, H., y WARD PERKINS. B. (Eds.): Marble in Antiquity. Colledted Papers of J. B. Ward Perkins, Archaeological Monographs of the British School at Rome, n. ${ }^{\circ} 6$, ap. V, 23-30.

WIISON JONES, M. (1989): "Designing the Roman Corinthian order", Journal of Roman Archaeology,2, 35-69.

WURCH-KOZEL,J, M. (1988): "Methods of Transporting Blocks in Antiquity", en HERZ, N., y WAELKENS, M.: Classical Marble: Geochemistry, Technology, Trade, Dordrecht, 55-64. 